Cochrane Database of Systematic Reviews

\title{
Interventionist versus expectant care for severe pre-eclampsia between 24 and 34 weeks' gestation (Review)
}

Churchill D, Duley L, Thornton JG, Moussa M, Ali HSM, Walker KF

Churchill D, Duley L, Thornton JG, Moussa M, Ali HSM, Walker KF.

Interventionist versus expectant care for severe pre-eclampsia between 24 and 34 weeks' gestation.

Cochrane Database of Systematic Reviews 2018, Issue 10. Art. No.: CD003106.

DOI: 10.1002/14651858.CD003106.pub3.

www.cochranelibrary.com

Interventionist versus expectant care for severe pre-eclampsia between 24 and 34 weeks' gestation (Review) 
TABLE OF CONTENTS

ABSTRAC

PLAIN LANGUAGE SUMMARY

SUMMARY OF FINDINGS

BACKGROUND

OBJECTIVES

METHODS

RESULTS

Figure 1.

Figure 2.

Figure 3.

DISCUSSION

AUTHORS' CONCLUSIONS

ACKNOWLEDGEMENTS

REFERENCES

CHARACTERISTICS OF STUDIES

DATA AND ANALYSES

Analysis 1.1. Comparison 1 Interventionist care versus expectant (delayed delivery) care for severe pre-eclampsia, Outcome 1 Maternal death.

Analysis 1.2. Comparison 1 Interventionist care versus expectant (delayed delivery) care for severe pre-eclampsia, Outcome 2 Eclampsia.

Analysis 1.3. Comparison 1 Interventionist care versus expectant (delayed delivery) care for severe pre-eclampsia, Outcome 3 Pulmonary oedema.

Analysis 1.4. Comparison 1 Interventionist care versus expectant (delayed delivery) care for severe pre-eclampsia, Outcome 4 HELLP syndrome.

Analysis 1.5. Comparison 1 Interventionist care versus expectant (delayed delivery) care for severe pre-eclampsia, Outcome 5 Death of the baby (all stillbirths, neonatal, and infant deaths).

Analysis 1.6. Comparison 1 Interventionist care versus expectant (delayed delivery) care for severe pre-eclampsia, Outcome 6 Death of the baby (subgrouped by time of death).

Analysis 1.7. Comparison 1 Interventionist care versus expectant (delayed delivery) care for severe pre-eclampsia, Outcome 7 Intraventricular haemorrhage or hypoxic ischaemic encephalopathy.

Analysis 1.8. Comparison 1 Interventionist care versus expectant (delayed delivery) care for severe pre-eclampsia, Outcome 8 Caesarean section.

Analysis 1.9. Comparison 1 Interventionist care versus expectant (delayed delivery) care for severe pre-eclampsia, Outcome 9 Renal failure.

Analysis 1.10. Comparison 1 Interventionist care versus expectant (delayed delivery) care for severe pre-eclampsia, Outcome 10 Placental abruption.

Analysis 1.11. Comparison 1 Interventionist care versus expectant (delayed delivery) care for severe pre-eclampsia, Outcome 11 Hyaline membrane disease.

Analysis 1.12. Comparison 1 Interventionist care versus expectant (delayed delivery) care for severe pre-eclampsia, Outcome 12 Baby ventilated.

Analysis 1.13. Comparison 1 Interventionist care versus expectant (delayed delivery) care for severe pre-eclampsia, Outcome 13 Gestation at birth (days).

Analysis 1.14. Comparison 1 Interventionist care versus expectant (delayed delivery) care for severe pre-eclampsia, Outcome 14 Necrotising enterocolitis.

Analysis 1.15. Comparison 1 Interventionist care versus expectant (delayed delivery) care for severe pre-eclampsia, Outcome 15 Small-for-gestational age.

Analysis 1.16. Comparison 1 Interventionist care versus expectant (delayed delivery) care for severe pre-eclampsia, Outcome 16 Low Apgar score at five minutes ( $<7$ at five minutes).

Analysis 1.17. Comparison 1 Interventionist care versus expectant (delayed delivery) care for severe pre-eclampsia, Outcome 17 Neonatal seizures.

Analysis 1.18. Comparison 1 Interventionist care versus expectant (delayed delivery) care for severe pre-eclampsia, Outcome 18 Measures of long-term growth \& development (cerebral palsy).

Analysis 1.19. Comparison 1 Interventionist care versus expectant (delayed delivery) care for severe pre-eclampsia, Outcome 19 Measures of long-term growth \& development (poor hearing, use of hearing aid). 
Analysis 1.20. Comparison 1 Interventionist care versus expectant (delayed delivery) care for severe pre-eclampsia, Outcome 20 Measures of long-term growth \& development (impaired vision).

Analysis 1.21. Comparison 1 Interventionist care versus expectant (delayed delivery) care for severe pre-eclampsia, Outcome 21 Admission to neonatal intensive care unit.

Analysis 1.22. Comparison 1 Interventionist care versus expectant (delayed delivery) care for severe pre-eclampsia, Outcome 22 Length of stay in neonatal intensive care unit (days).

APPENDICES

WHAT'S NEW

HISTORY

CONTRIBUTIONS OF AUTHORS

DECLARATIONS OF INTEREST

SOURCES OF SUPPORT

DIFFERENCES BETWEEN PROTOCOL AND REVIEW

INDEX TERMS 
[Intervention Review]

\section{Interventionist versus expectant care for severe pre-eclampsia between 24 and 34 weeks' gestation}

David Churchill ${ }^{1}$, Lelia Duley², Jim G Thornton ${ }^{3}$, Mahmoud Moussa ${ }^{1,4}$, Hind SM Ali5, Kate F Walker ${ }^{3}$

1Department of Obstetrics and Gynaecology, The Royal Wolverhampton Hospitals NHS Trust, Wolverhampton, UK. 2 Nottingham Clinical Trials Unit, Nottingham Health Science Partners, Nottingham, UK. ${ }^{3}$ Division of Child Health, Obstetrics and Gynaecology, School of Medicine, University of Nottingham, Nottingham, UK. ${ }^{4}$ Department of Obstetrics and Gynaecology, Ain Shams University, Cairo, Egypt. 5Department of Obstetrics and Gynaecology, New Cross Hospital, Royal Wolverhampton NHS Trust, Wolverhampton, UK

Contact: David Churchill, Department of Obstetrics and Gynaecology, The Royal Wolverhampton Hospitals NHS Trust, New Cross Hospital, Wednesfield, Wolverhampton, West Midlands, WV10 0QP, UK. david.churchill1@nhs.net.

Editorial group: Cochrane Pregnancy and Childbirth Group.

Publication status and date: New search for studies and content updated (no change to conclusions), published in Issue 10, 2018.

Citation: Churchill D, Duley L, Thornton JG, Moussa M, Ali HSM, Walker KF. Interventionist versus expectant care for severe preeclampsia between 24 and 34 weeks' gestation. Cochrane Database of Systematic Reviews 2018, Issue 10. Art. No.: CD003106. DOI: 10.1002/14651858.CD003106.pub3.

Copyright @ 2018 The Cochrane Collaboration. Published by John Wiley \& Sons, Ltd.

\section{A B S T R A C T}

\section{Background}

Severe pre-eclampsia can cause significant mortality and morbidity for both mother and child, particularly when it occurs remote from term, between 24 and 34 weeks' gestation. The only known cure for this disease is delivery. Some obstetricians advocate early delivery to ensure that the development of serious maternal complications, such as eclampsia (fits) and kidney failure are prevented. Others prefer a more expectant approach, delaying delivery in an attempt to reduce the mortality and morbidity for the child that is associated with being born too early.

\section{Objectives}

To evaluate the comparative benefits and risks of a policy of early delivery by induction of labour or by caesarean section, after sufficient time has elapsed to administer corticosteroids, and allow them to take effect; with a policy of delaying delivery (expectant care) for women with severe pre-eclampsia between 24 and 34 weeks' gestation.

\section{Search methods}

For this update, we searched Cochrane Pregnancy and Childbirth's Trials Register, ClinicalTrials.gov, the WHO International Clinical Trials Registry Platform (ICTRP) on 27 November 2017, and reference lists of retrieved studies.

\section{Selection criteria}

Randomised trials comparing the two intervention strategies for women with early onset, severe pre-eclampsia. Trials reported in an abstract were eligible for inclusion, as were cluster-trial designs. We excluded quasi-randomised trials.

\section{Data collection and analysis}

Three review authors independently assessed trials for inclusion and risk of bias, extracted data, and checked them for accuracy. We assessed the quality of the evidence for specified outcomes using the GRADE approach.

\section{Main results}

We included six trials, with a total of 748 women in this review. All trials included women in whom there was no overriding indication for immediate delivery in the fetal or maternal interest. Half of the trials were at low risk of bias for methods of randomisation and 
allocation concealment; and four trials were at low risk for selective reporting. For most other domains, risk of bias was unclear. There were insufficient data for reliable conclusions about the comparative effects on most outcomes for the mother. Two studies reported on maternal deaths; neither study reported any deaths (two studies; 320 women; low-quality evidence). It was uncertain whether interventionist care reduced eclampsia (risk ratio (RR) $0.98,95 \%$ confidence interval $(\mathrm{Cl}) 0.06$ to 15.58; two studies; 359 women) or pulmonary oedema (RR $0.45,95 \% \mathrm{Cl} 0.07$ to 3.00; two studies; 415 women), because the quality of the evidence for these outcomes was very low. Evidence from two studies suggested little or no clear difference between the interventionist and expectant care groups for HELLP (haemolysis, elevated liver enzymes, and low platelets) syndrome (RR 1.09, 95\% Cl 0.62 to 1.91; two studies; 359 women; low-quality evidence). No study reported on stroke. With the addition of data from two studies for this update, there was now evidence to suggest that interventionist care probably made little or no difference to the incidence of caesarean section (average RR $1.01,95 \% \mathrm{Cl} 0.91$ to 1.12 ; six studies; 745 women; Heterogeneity: $\left.\operatorname{Tau}^{2}=0.01 ; 1^{2}=63 \%\right)$.

For the baby, there was insufficient evidence to draw reliable conclusions about the effects on perinatal deaths (RR $1.11,95 \% \mathrm{Cl} 0.62$ to 1.99; three studies; 343 women; low-quality evidence). Babies whose mothers had been allocated to the interventionist group had more intraventricular haemorrhage (RR 1.94, $95 \% \mathrm{Cl} 1.15$ to 3.29; two studies; 537 women; moderate-quality evidence), more respiratory distress caused by hyaline membrane disease ( $\mathrm{RR} 2.30,95 \% \mathrm{Cl} 1.39$ to 3.81 ; two studies; 133 women), required more ventilation (RR $1.50,95 \% \mathrm{Cl}$ 1.11 to 2.02; two studies; 300 women), and were more likely to have a lower gestation at birth (mean difference (MD) -9.91 days, $95 \% \mathrm{Cl}$ -16.37 to -3.45 days; four studies; 425 women; Heterogeneity: Tau $^{2}=31.74 ; I^{2}=76 \%$ ). However, babies whose mothers had been allocated to the interventionist group were no more likely to be admitted to neonatal intensive care (average RR $1.19,95 \% \mathrm{Cl} 0.89$ to 1.60 ; three studies; 400 infants; Heterogeneity: Tau $\left.^{2}=0.05 ; \mathrm{I}^{2}=84 \%\right)$. Babies born to mothers in the interventionist groups were more likely to have a longer stay in the neonatal intensive care unit (MD 7.38 days, $95 \% \mathrm{Cl}-0.45$ to 15.20 days; three studies; 400 women; Heterogeneity: Tau ${ }^{2}$ $=40.93, \mathrm{I}^{2}=85 \%$ ) and were less likely to be small-for-gestational age (RR $0.38,95 \% \mathrm{Cl} 0.24$ to 0.61 ; three studies; 400 women). There were no clear differences between the two strategies for any other outcomes.

\section{Authors' conclusions}

This review suggested that an expectant approach to the management of women with severe early onset pre-eclampsia may be associated with decreased morbidity for the baby. However, this evidence was based on data from only six trials. Further large, high-quality trials are needed to confirm or refute these findings, and establish if this approach is safe for the mother.

\section{PLAIN LANGUAGE SUMMARY}

\section{Interventionist versus expectant care for severe pre-eclampsia before term}

\section{What is the issue?}

Women who develop pre-eclampsia (high blood pressure and protein in the urine) before 34 weeks of pregnancy (early onset) are at risk of severe complications, and even death. These involve the woman's liver, kidneys, and clotting system, and cause neurological disturbances, such as headache, visual disturbances, and fits. If the placenta is involved, this can cause growth restriction or reduced amniotic fluid, placing the baby at risk.

\section{Why is this important?}

The only known cure for pre-eclampsia is delivery of the baby. Being born too early can in itself have problems for the baby, even with the administration of corticosteroids 24 to 48 hours beforehand, to help mature the lungs. Some hospitals follow a policy of early delivery, within 24 to 48 hours, called interventionist management, whilst others prefer to delay delivery until it is no longer possible to safely stabilise the woman's condition, called expectant management.

\section{What evidence did we find?}

We searched for evidence in November 2017 and identified six randomised trials. This review included six trials that randomly assigned women to a policy of interventionist management or expectant management when presenting with severe pre-eclampsia before 34 weeks of pregnancy. A total of 748 women were included in these six trials. Babies born to women allocated to an interventionist approach were probably more likely to experience adverse effects such as bleeding in the brain (intraventricular haemorrhage). They may also have been more likely to require ventilation, have a longer stay in the neonatal unit, have a lower gestation at birth in days, and weigh less at birth than those babies born to women allocated to an expectant management approach. There was insufficient evidence for reliable conclusions about the effects on perinatal deaths. Babies whose mothers had been allocated to the interventionist group were no more likely to be admitted to neonatal intensive care.

There were no maternal deaths in the two studies that reported this outcome. The evidence was very low-quality for the outcome of fits or convulsions (eclampsia), or of fluid in the lungs (pulmonary oedema), and so it was uncertain whether interventionist care made any clear difference to the mothers' health. Evidence from two studies suggested little or no clear difference between the interventionist and expectant care groups for a severe form of pre-eclampsia, which affects the liver and blood clotting, called HELLP syndrome, which stands for haemolysis (breakdown of red blood cells), elevated liver enzymes (a sign of liver damage), and low platelets (platelets help the blood 
to clot). None of the studies reported on the incidence of stroke in the mother. With the addition of data from two studies for this update, there was now evidence to suggest that interventionist care probably made little or no difference to the caesarean section rate.

\section{What does this mean?}

In the absence of an over-riding maternal or fetal indication for immediate delivery, delay may be more beneficial for the baby. However, there were insufficient data to enable us to draw reliable conclusions about the comparative effects on most outcomes for the mother, and hence the maternal safety of an expectant approach.

This evidence was based on data from only six trials. Further large trials with long-term follow-up of the children are needed to confirm or refute whether expectant care is better than early delivery for women who suffer from severe pre-eclampsia before 34 weeks of pregnancy. 
SUMMARY OF FINDINGS

Summary of findings for the main comparison. Interventionist care compared to expectant (delayed delivery) care for severe pre-eclampsia for severe pre-eclampsia between 24 and 34 weeks' gestation

Interventionist care compared to expectant (delayed delivery) care for severe pre-eclampsia

Patient or population: women with severe pre-eclampsia between 24 and 34 weeks' gestation

Setting: hospital settings

Intervention: interventionist care

Comparison: expectant (delayed delivery) care

\begin{tabular}{|c|c|c|c|c|c|c|}
\hline \multirow[t]{2}{*}{ Outcomes } & \multicolumn{2}{|c|}{ Anticipated absolute effects ${ }^{\star}(95 \% \mathrm{Cl})$} & \multirow{2}{*}{$\begin{array}{l}\text { Relative effect } \\
(95 \% \mathrm{CI})\end{array}$} & \multirow{2}{*}{$\begin{array}{l}\text { № of partici- } \\
\text { pants } \\
\text { (studies) }\end{array}$} & \multirow{2}{*}{$\begin{array}{l}\text { Certainty of } \\
\text { the evidence } \\
\text { (GRADE) }\end{array}$} & \multirow[t]{2}{*}{ Comments } \\
\hline & $\begin{array}{l}\text { Risk with expectant } \\
\text { (delayed delivery) } \\
\text { care }\end{array}$ & Risk with Interventionist care & & & & \\
\hline \multirow[t]{2}{*}{ Maternal death } & \multicolumn{2}{|l|}{ Study population } & \multirow[t]{2}{*}{ not estimable } & \multirow{2}{*}{$\begin{array}{l}320 \\
\text { (2 RCTs) }\end{array}$} & \multirow{2}{*}{$\begin{array}{l}\oplus \oplus \odot \ominus \\
\mathrm{LOW} a, b\end{array}$} & \multirow{2}{*}{$\begin{array}{l}\text { There were no } \\
\text { deaths in either } \\
\text { group }\end{array}$} \\
\hline & 0 per 1000 & $\begin{array}{l}0 \text { per } 1000 \\
(0 \text { to } 0)\end{array}$ & & & & \\
\hline \multirow[t]{2}{*}{ Eclampsia } & \multicolumn{2}{|l|}{ Study population } & \multirow{2}{*}{$\begin{array}{l}\text { RR } 0.98 \\
\text { (0.06 to } 15.58)\end{array}$} & \multirow{2}{*}{$\begin{array}{l}359 \\
\text { (2 RCTs) }\end{array}$} & \multirow{2}{*}{$\begin{array}{l}\oplus \odot \odot \odot \\
\text { VERY LOW c,d }\end{array}$} & \\
\hline & 6 per 1000 & $\begin{array}{l}5 \text { per } 1000 \\
(0 \text { to } 87)\end{array}$ & & & & \\
\hline Stroke (brain damage) & - & - & - & - & - & $\begin{array}{l}\text { outcome not re- } \\
\text { ported }\end{array}$ \\
\hline HELLP syndrome & 111 per 1000 & $\begin{array}{l}121 \text { per } 1000 \\
\text { (69 to } 212)\end{array}$ & $\begin{array}{l}\text { RR } 1.09 \\
\text { (0.62 to } 1.91 \text { ) }\end{array}$ & $\begin{array}{l}359 \\
\text { (2 RCTs) }\end{array}$ & $\begin{array}{l}\oplus \oplus \Theta \Theta \\
\text { LOW c,e }\end{array}$ & \\
\hline \multirow[t]{2}{*}{ Pulmonary oedema } & \multicolumn{2}{|l|}{ Study population } & \multirow{2}{*}{$\begin{array}{l}\text { RR } 0.45 \\
\text { (0.07 to } 3.00)\end{array}$} & \multirow{2}{*}{$\begin{array}{l}415 \\
\text { (3 RCTs) }\end{array}$} & \multirow{2}{*}{$\begin{array}{l}\oplus \ominus \ominus \ominus \\
\text { VERY LOW c,f }\end{array}$} & \\
\hline & 10 per 1000 & $\begin{array}{l}4 \text { per } 1000 \\
(1 \text { to } 29)\end{array}$ & & & & \\
\hline \multirow{2}{*}{$\begin{array}{l}\text { Perinatal mortality or } \\
\text { perinatal death }\end{array}$} & \multicolumn{2}{|l|}{ Study population } & \multirow{2}{*}{$\begin{array}{l}\text { RR } 1.11 \\
\text { (0.62 to } 1.99)\end{array}$} & \multirow{2}{*}{$\begin{array}{l}343 \\
\text { (3 RCTs) }\end{array}$} & \multirow{2}{*}{$\begin{array}{l}\oplus \oplus \odot \ominus \\
\text { LOW e,g }\end{array}$} & \\
\hline & 105 per 1000 & 117 per 1000 & & & & \\
\hline
\end{tabular}




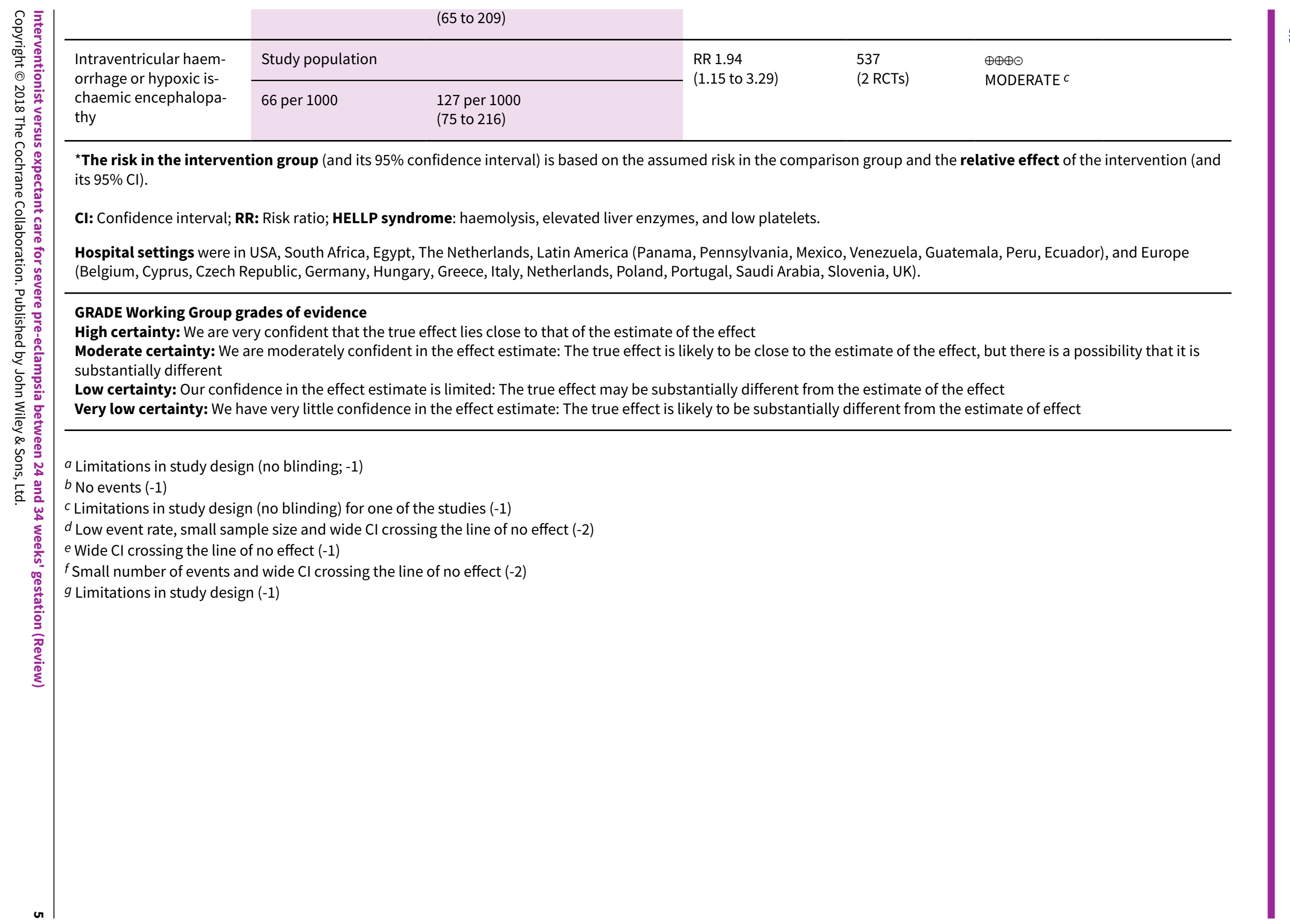




\section{B A C K G R O U N D}

Pre-eclampsia is a multisystem disorder that is usually associated with raised blood pressure and proteinuria, but can also involve the woman's liver, kidneys, clotting system, or brain. If the placenta is involved, this may lead to growth restriction or premature birth. Pre-eclampsia is a relatively common complication of pregnancy, and can occur at any time during the second half of pregnancy, or in the first few weeks after delivery. Prediction models for adverse maternal outcome have been developed and validated in recent times, but there is still a paucity of data to guide the clinician on the timing of delivery to ensure safety of both the mother and the baby in the long term (von Dadelszen 2011). Pre-eclampsia is described in more detail in the generic protocol on interventions for treatment of pre-eclampsia and its consequences (Duley 2009).

\section{Description of the condition}

Hypertension in pregnancy is defined as a systolic blood pressure of $140 \mathrm{mmHg}$ or more, a diastolic pressure of $90 \mathrm{mmHg}$ or more, or both. To be diagnosed with pre-eclampsia, the hypertension has to rise de novo after 20 weeks of pregnancy, combined with proteinuria, defined as more than $300 \mathrm{mg}$ of total protein in a 24hour urine collection (Davey 1988). Proteinuria can also be assessed using a spot urine test, which measures the protein to creatinine ratio. A protein:creatinine ratio of $30 \mathrm{mg} / \mathrm{mmol}$ correlates with a 24-hour protein excretion of more than $300 \mathrm{mg}$ in 24 hours (Morris 2012). This method of estimating the amount of protein being excreted has several advantages over the 24-hour urine collection, and was endorsed by NICE (NICE 2010). However, pre-eclampsia is a multi-system disorder, and the diagnosis of hypertension and proteinuria is considered to be too restrictive for clinical practice. Clinicians are all too aware that the disease can present in several ways, and it is necessary to be vigilant when assessing women with symptoms and signs that are strongly associated with the disease. This has led to a widening of the definition for clinical purposes, to include the following: de novo hypertension after 20 weeks' gestation, and new onset of one of the following: a) proteinuria, as defined above; b) renal insufficiency (creatinine $\geq 0.09 \mathrm{mmol} / \mathrm{L}$, or oliguria; c) liver disease (raised transaminases, severe right upper quadrant or epigastric pain, or a combination); d) neurological problems: convulsions (eclampsia), hyper-reflexia with clonus (involuntary muscular contractions), severe headaches, persistent visual disturbances (scotoma); e) haematological disturbances: thrombocytopenia (reduced numbers of platelets), disseminated intravascular coagulation, haemolysis; or $\mathrm{f}$ ) fetal growth restriction (Brown 2001).

There is no widely accepted definition of severe pre-eclampsia (Duley 2009). Nevertheless, the features described above, in combination with the early onset of the disease between 24 and 34 weeks' gestation, would be considered by most clinicians to represent severe pre-eclampsia. Therefore, we did not define further or categorise 'severity'.

\section{Description of the intervention}

In clinical practice, some units advocate early delivery, which has been referred to as 'aggressive management' (Sibai 1984). In this review, we prefer the term 'interventionist'. This means delivery by either induction of labour or caesarean section, after corticosteroids have been given to improve fetal lung maturation, which in practice, is after 24 to 48 hours (Crowley 1996; Roberts
2013). Others prefer to give corticosteroids, stabilise the woman's condition and then, if possible, aim to delay delivery. This is usually known as 'expectant management' (Derham 1989). The greatest dilemma in deciding when to deliver, is balancing the risks to mother and baby when the pregnancy is somewhere between 24 and 34 weeks. Early delivery results in a very premature baby, which could lead to more neonatal complications, such as respiratory distress syndrome sometimes called hyaline membrane disease (difficulty in breathing and oxygenation), intraventricular haemorrhage (bleeding into the cavities of the brain), and necrotising enterocolitis (bleeding into the wall of the bowel due to a lack of oxygen). Conversely, delaying delivery in an attempt to allow fetal maturation could place the mother in jeopardy, and at risk of multisystem organ failure as outlined above. It also prolongs the time that a fetus is in a potentially hostile in utero environment. This in turn, will continue to adversely affect the growth of the fetus, and may result in an intrauterine death from severe hypoxia, or an acute event such as an abruption. Although the precise cutoffs for gestational age will vary with different settings, before 24 weeks, the child has little chance of survival. After 34 weeks, the prognosis improves, with nearly $100 \%$ survival. Between 24 and 34 weeks, mortality decreases with increasing gestational age, but below 28 weeks, there is considerable risk of survival with severe disability. A structured review of observational studies found that expectant care for severe pre-eclampsia, with a prolongation of the pregnancy by between one and two weeks, was associated with better outcomes for babies and low risks for the mother. There were fewer neonatal deaths and complications of prematurity (Magee 2009).

\section{How the intervention might work}

The review compared the merits of two management strategies for sever pre-eclampsia distant from term. It endeavoured to discover if one of the strategies: interventionist management, i.e. early delivery, or expectant management, i.e. delaying delivery until there was a specific maternal or fetal indication to intervene, conferred an advantage to the baby, mother, or both, without causing undue risks of morbidity or mortality to one of them. This means, improving the intact survival rates of preterm babies without increasing serious morbidity and mortality for the mother.

\section{Why it is important to do this review}

This difficult clinical dilemma occurs relatively frequently in large units, and currently, decisions are based mainly upon personal experience rather than good evidence. There is a great need for reliable data to help inform this decision-making.

Other aspects of care for women with severe pre-eclampsia are dealt with in other reviews. These include drugs for lowering very high blood pressure (Duley 2013), prophylactic anticonvulsants (Duley 2010), and plasma volume expansion (Duley 1999b). Prevention of pre-eclampsia is covered by reviews of calcium supplementation (Hofmeyr 2014), antiplatelets (Duley 2007), salt intake (Duley 1999a; Duley 2005), and magnesium supplementation (Makrides 2014).

\section{O B JECT IVES}

To evaluate the comparative benefits and risks of a policy of early delivery by induction of labour or by caesarean section, after sufficient time has elapsed to administer corticosteroids, and allow 
them to take effect; with a policy of delaying delivery (expectant care) for women with severe pre-eclampsia between 24 and 34 weeks' gestation.

\section{METHODS}

\section{Criteria for considering studies for this review}

\section{Types of studies}

All adequately randomised trials comparing interventionist (aggressive) with expectant care (delayed delivery) for women with severe early onset pre-eclampsia. We excluded quasi-random designs, such as alternate numbers or allocation by the day of the week. Trials reported in an abstract were eligible for inclusion, as were cluster-trial designs.

\section{Types of participants}

Women with severe pre-eclampsia who were up to, and including, 34 weeks' gestation. Severe pre-eclampsia was defined as:

- high blood pressure ( $\geq 140 / 90 \mathrm{mmHg}$ ) on two consecutive occasions four or more hours apart, plus proteinuria higher than $300 \mathrm{mg} / 24$ hours; or

- severe hypertension (blood pressure at least $160 \mathrm{mmHg}$ systolic, or $110 \mathrm{mmHg}$ diastolic) alone; or

- hypertension as defined above, plus one or more of the following criteria:

- severe proteinuria (usually at least $3 \mathrm{~g}$ (range $2 \mathrm{~g}$ to $5 \mathrm{~g}$ ) protein in 24 hours, or $3+$ on dipstick);

- reduced urinary volume (less than $500 \mathrm{~mL}$ in 24 hours), upper abdominal pain, pulmonary oedema;

- neurological disturbances (such as headache, visual disturbances, and exaggerated tendon reflexes);

- impaired liver function tests, high serum creatinine, low platelets); or

- suspected intrauterine growth restriction or reduced amniotic fluid.

This latter set of criteria reflect the natural history of the disease and clinical practice when diagnosing severe pre-eclampsia.

\section{Types of interventions}

Any comparison of a policy of early elective delivery by induction of labour or by caesarean section (interventionist management) with a policy of delayed delivery (expectant management). If corticosteroids were used in the trial, they should have been used for both types of care. As the beneficial effects of a course of corticosteroids are so important, we excluded any study where corticosteroids were only administered to one group but not the other.

\section{Types of outcome measures}

\section{Primary outcomes}

For the woman

- Death

- Eclampsia (fitting)

- Stroke (brain damage)

- HELLP (haemolysis, elevated liver enzymes, and low platelets) syndrome
- Pulmonary oedema (fluid in the lungs)

For the baby

- Stillbirth

- Neonatal death

- Intraventricular haemorrhage (bleeding in the brain), hypoxic ischaemic encephalopathy, or both

\section{Secondary outcomes}

For the woman

- Renal failure (kidney failure)

- Liver failure

- Cardiac arrest

- The need for invasive monitoring, such as central venous catheterisation (intravenous lines into the great veins around the heart)

- Caesarean section

- Placental abruption

\section{For the baby}

- Low Apgar score at five minutes

- Neonatal seizures

- Hyaline membrane disease sometimes referred to as Respiratory Distress Syndrome (stiff lungs)

- Pneumothorax (air leaks from the lungs)

- Necrotising enterocolitis (bleeding into the bowel wall)

- Ventilation (any ventilation, duration of ventilation)

- Measures of long-term growth and development, such as important impairment and cerebral palsy

- Small-for-gestational age

- Gestation at birth

Use of health service resources

- Need for intensive care for the woman

- Need for high-dependency care or observation, or both, for the woman

- Length of stay in neonatal intensive care

- Admission to neonatal intensive care unit

- Surfactant for the baby

- Ventilation for the baby

\section{Search methods for identification of studies}

The following methods section of this review is based on a standard template used by Cochrane Pregnancy and Childbirth.

\section{Electronic searches}

For this update, we searched Cochrane Pregnancy and Childbirth's Trials Register by contacting their Information Specialist (27 November 2017).

The Register is a database containing over 24,000 reports of controlled trials in the field of pregnancy and childbirth. It represents over 30 years of searching. For full current search methods used to populate Pregnancy and Childbirth's Trials Register, including the detailed search strategies for CENTRAL, MEDLINE, Embase, and CINAHL; the list of handsearched journals 
and conference proceedings, and the list of journals reviewed via the current awareness service, please follow this link to the editorial information about the Cochrane Pregnancy and Childbirth in the Cochrane Library, and select the 'Specialized Register' section from the options on the left side of the screen.

Briefly, Cochrane Pregnancy and Childbirth's Trials Register is maintained by their Information Specialist and contains trials identified from:

1. monthly searches of the Cochrane Central Register of Controlled Trials (CENTRAL);

2. weekly searches of MEDLINE (Ovid);

3. weekly searches of Embase (Ovid);

4. monthly searches of CINAHL (EBSCO);

5. handsearches of 30 journals and the proceedings of major conferences;

6. weekly current awareness alerts for a further 44 journals, plus monthly BioMed Central email alerts.

Search results are screened by two people and the full text of all relevant trial reports identified through the searching activities described above is reviewed. Based on the intervention described, each trial report is assigned a number that corresponds to a specific Pregnancy and Childbirth review topic (or topics), and is then added to the Register. The Information Specialist searches the Register for each review using this topic number rather than keywords. This results in a more specific search set that has been fully accounted for in the relevant review sections (Included studies; Excluded studies; Studies awaiting classification; Ongoing studies).

In addition, we searched ClinicalTrials.gov and the WHO International Clinical Trials Registry Platform (ICTRP) for unpublished, planned, and ongoing trial reports (27 November 2017) using the methods detailed in Appendix 1.

\section{Searching other resources}

We searched the reference lists of retrieved studies.

We did not apply any language or date restrictions.

\section{Data collection and analysis}

For methods used in the previous version of this review, see Churchill 2013.

For this update, the following methods were used to assess the five reports that were identified as a result of the updated search.

The following methods section of this review is based on a standard template used by Cochrane Pregnancy and Childbirth.

\section{Selection of studies}

Three review authors independently assessed for inclusion all the potential studies identified as a result of the search strategy. We resolved any disagreement through discussion, or if required, we consulted a fourth review author.

\section{Data extraction and management}

We designed a form to extract data. For eligible studies, three review authors independently extracted the data, using the agreed form. We resolved discrepancies through discussion, or if required, we consulted a fourth review author. We entered data into Review Manager 5 software (RevMan 2014), and checked for accuracy.

When information regarding any of the above was unclear, we contacted authors of the original reports to provide further details.

\section{Assessment of risk of bias in included studies}

Three review authors independently assessed risk of bias for each study using the criteria outlined in the Cochrane Handbook for Systematic Reviews of Interventions (Higgins 2011). They resolved disagreements by discussion, or by involving a fourth assessor.

\section{(1) Random sequence generation (checking for possible selection bias)}

We described the method used to generate the allocation sequence in sufficient detail to allow an assessment of whether it should produce comparable groups.

For each included study, we assessed the method as being at:

- low risk of bias (any truly random process, e.g. random number table; computer random number generator);

- high risk of bias (any non-random process, e.g. odd or even date of birth; hospital or clinic record number);

- unclear risk of bias.

\section{(2) Allocation concealment (checking for possible selection bias)}

For each included study, we described the method used to conceal allocation to interventions prior to assignment, and assessed whether intervention allocation could have been foreseen in advance of, or during recruitment, or changed after assignment.

We assessed the methods as being at:

- low risk of bias (e.g. telephone or central randomisation; consecutively numbered sealed opaque envelopes);

- high risk of bias (open random allocation; unsealed or nonopaque envelopes, alternation; date of birth);

- unclear risk of bias.

\section{(3.1) Blinding of participants and personnel (checking for possible performance bias)}

For each included study, we described the methods used, if any, to blind study participants and personnel from knowledge of which intervention a participant received. We considered that studies were at low risk of bias if they were blinded, or if we judged that the lack of blinding was unlikely to affect results. We assessed blinding separately for different outcomes or classes of outcomes.

We assessed the methods as being at:

- low, high, or unclear risk of bias for participants;

- low, high, or unclear risk of bias for personnel.

\section{(3.2) Blinding of outcome assessment (checking for possible} detection bias)

For each included study, we described the methods used, if any, to blind outcome assessors from knowledge of which intervention a participant received. We assessed blinding separately for different outcomes or classes of outcomes. 
We assessed methods used to blind outcome assessment as being at:

- low, high, or unclear risk of bias.

\section{(4) Incomplete outcome data (checking for possible attrition bias due to the amount, nature and handling of incomplete outcome data)}

For each included study, and for each outcome or class of outcomes, we described the completeness of data, including attrition and exclusions from the analysis. We stated whether attrition and exclusions were reported, and the numbers included in the analysis at each stage (compared with the total randomised participants), reasons for attrition or exclusion where reported, and whether missing data were balanced across groups or were related to outcomes. Where sufficient information was reported, or could be supplied by the trial authors, we planned to re-include missing data in the analyses that we undertook.

We assessed methods as being at:

- low risk of bias (e.g. no missing outcome data; missing outcome data balanced across groups);

- high risk of bias (e.g. numbers or reasons for missing data imbalanced across groups; 'as treated' analysis done with substantial departure of intervention received from that assigned at randomisation);

- unclear risk of bias.

\section{(5) Selective reporting (checking for reporting bias)}

For each included study, we described how we investigated the possibility of selective outcome reporting bias and what we found.

We assessed the methods as being at:

- low risk of bias (where it was clear that all of the study's prespecified outcomes and all expected outcomes of interest to the review were reported);

- high risk of bias (where not all the study's prespecified outcomes were reported; one or more reported primary outcomes were not prespecified; outcomes of interest were reported incompletely, and so could not be used; study failed to include results of a key outcome that would have been expected to have been reported);

- unclear risk of bias.

(6) Other bias (checking for bias due to problems not covered by (1) to (5) above)

For each included study, we described any important concerns we had about other possible sources of bias.

\section{(7) Overall risk of bias}

We made explicit judgements about whether studies were at high risk of bias, according to the criteria given in the Cochrane Handbook for Systematic Reviews of Interventions (Higgins 2011). With reference to (1) to (6) above, we had planned to assess the likely magnitude and direction of the bias and whether we considered it was likely to have an impact on the findings. In future updates, we will explore the impact of the level of bias through undertaking sensitivity analyses (Sensitivity analysis).

\section{Assessment of the quality of the evidence using the GRADE approach}

For this update, we assessed the quality of the evidence using the GRADE approach, as outlined in the GRADE Handbook, in order to assess the quality of the body of evidence relating to the following outcomes for the main comparison, interventionist care versus expectant (GRADE Handbook).

\section{For the woman}

- Death

- Eclampsia (fitting)

- Stroke (brain damage)

- HELLP (haemolysis, elevated liver enzymes and low platelets) syndrome

- Pulmonary oedema (fluid in the lungs)

\section{For the baby}

- Perinatal mortality

- Intraventricular haemorrhage (bleeding in the brain), hypoxic ischaemic encephalopathy, or both

We used the GRADEpro GDT to import data from Review Manager 5.3 in order to create 'Summary of findings' tables (GRADEpro GDT; RevMan 2014). We produced a summary of the intervention effect and a measure of quality for each of the above outcomes, using the GRADE approach. The GRADE approach uses five considerations (study limitations, consistency of effect, imprecision, indirectness, and publication bias) to assess the quality of the body of evidence for each outcome. The evidence can be downgraded from high quality by one level for serious (or by two levels for very serious) limitations, depending on assessments for risk of bias, indirectness of evidence, serious inconsistency, imprecision of effect estimates, or potential publication bias.

\section{Measures of treatment effect}

\section{Dichotomous data}

For dichotomous data, we presented results as summary risk ratio with $95 \%$ confidence intervals.

\section{Continuous data}

We used the mean difference if outcomes were measured in the same way between trials. We used the standardised mean difference to combine trials that measured the same outcome, but used different methods.

\section{Unit of analysis issues}

\section{Cluster-randomised trials}

We did not identify any cluster-randomised trials for inclusion. If we identify cluster-randomised trials in future updates, we will include them in the analyses along with individually-randomised trials. We will adjust their sample sizes, using the methods described in the Cochrane Handbook for Systematic Reviews of Interventions, using an estimate of the intracluster correlation co-efficient (ICC) derived from the trial (if possible), from a similar trial, or from a study of a similar population. If we use ICCs from other sources, we will report this, and conduct sensitivity analyses to investigate the effect of variation in the ICC. If we identify both cluster-randomised trials and individually-randomised trials, we plan to synthesise the 
relevant information. We will consider it reasonable to combine the results from both if there is little heterogeneity between the study designs, and the interaction between the effect of the intervention and the choice of randomisation unit is considered to be unlikely.

We will also acknowledge heterogeneity in the randomisation unit, and perform a sensitivity analysis to investigate the effects of the randomisation unit.

\section{Cross-over trials}

Cross-over trials are not a valid study design for this review.

\section{Dealing with missing data}

For included studies, we noted levels of attrition. In future updates, if more eligible studies are included, we will explore the impact of including studies with high levels of missing data in the overall assessment of treatment effect by using sensitivity analyses.

For all outcomes, we carried out analyses, as far as possible, on an intention-to-treat basis, i.e. we attempted to include all participants randomised to each group in the analyses. The denominator for each outcome in each trial was the number randomised minus any participants whose outcomes were known to be missing.

\section{Assessment of heterogeneity}

We assessed statistical heterogeneity in each meta-analysis using $\mathrm{Tau}^{2}, \mathrm{I}^{2}$, and $\mathrm{Chi}^{2}$ statistics. We regarded heterogeneity as substantial if $\mathrm{I}^{2}$ was greater than $30 \%$, and either $\mathrm{Tau}^{2}$ was greater than zero, or there was a low $\mathrm{P}$ value (less than 0.10 ) in the $\mathrm{Chi}^{2}$ test for heterogeneity. If we identified substantial heterogeneity (above $30 \%$ ), we had planned to explore it by prespecified subgroup analysis, assuming we had sufficient data.

\section{Assessment of reporting biases}

In future updates, if there are 10 or more studies in the metaanalysis, we will investigate reporting biases (such as publication bias) using funnel plots. We will assess funnel plot asymmetry visually. If asymmetry is suggested by a visual assessment, we will perform exploratory analyses to investigate it.

\section{Data synthesis}

We carried out statistical analysis using Review Manager 5 software (RevMan 2014). We used fixed-effect meta-analysis to combine data where it was reasonable to assume that studies were estimating the same underlying treatment effect: i.e. where trials were examining the same intervention, and the trials' populations and methods were judged sufficiently similar.

If there was clinical heterogeneity sufficient to expect that the underlying treatment effects differed between trials, or if substantial statistical heterogeneity was detected, we used random-effects meta-analysis to produce an overall summary if an average treatment effect across trials was considered clinically meaningful. The random-effects summary was treated as the average of the range of possible treatment effects, and we had planned to discuss the clinical implications of treatment effects differing between trials. If the average treatment effect is not clinically meaningful, we will not combine trials. If we used randomeffects analyses, we presented the results as the average treatment effect with 95\% confidence intervals, and the estimates of $\mathrm{Tau}^{2}$ and $1^{2}$.

\section{Subgroup analysis and investigation of heterogeneity}

In future updates, if we identify substantial heterogeneity and have sufficient data, we will investigate it using subgroup and sensitivity analyses. We will consider whether an overall summary is meaningful, and if it is, use random-effects analysis to produce it.

We plan to carry out the following subgroup analyses based on:

1. gestation at trial entry: 24 to 28 weeks' gestation; 29 to 34 weeks' gestation; gestation mixed or unknown;

2. suspected intrauterine growth restriction at trial entry: suspected intrauterine growth restriction; no suspected intrauterine growth restriction; mixed or unknown.

We will explore the following primary outcomes in subgroup analyses.

\section{For the woman}

- Death

- Eclampsia (fitting)

- Stroke (brain damage)

- HELLP syndrome

- Pulmonary oedema

\section{For the baby}

- Stillbirth

- Neonatal death

- Intraventricular haemorrhage

We will assess differences between subgroups using interaction tests available in Review Manager 5.

\section{Sensitivity analysis}

In future updates, if we identify more studies to include in analyses, we plan to carry out sensitivity analyses to explore the effect of risk of bias assessed by concealment of allocation, high attrition rates, or both, with studies at high risk of bias being excluded from the analyses in order to assess whether this makes any difference to the overall result.

\section{RES U LTS}

\section{Description of studies}

\section{Results of the search}

See: Figure 1. 


\section{Figure 1. Study flow diagram}

Four studies included in the previous version of the review (Churchill 2013).

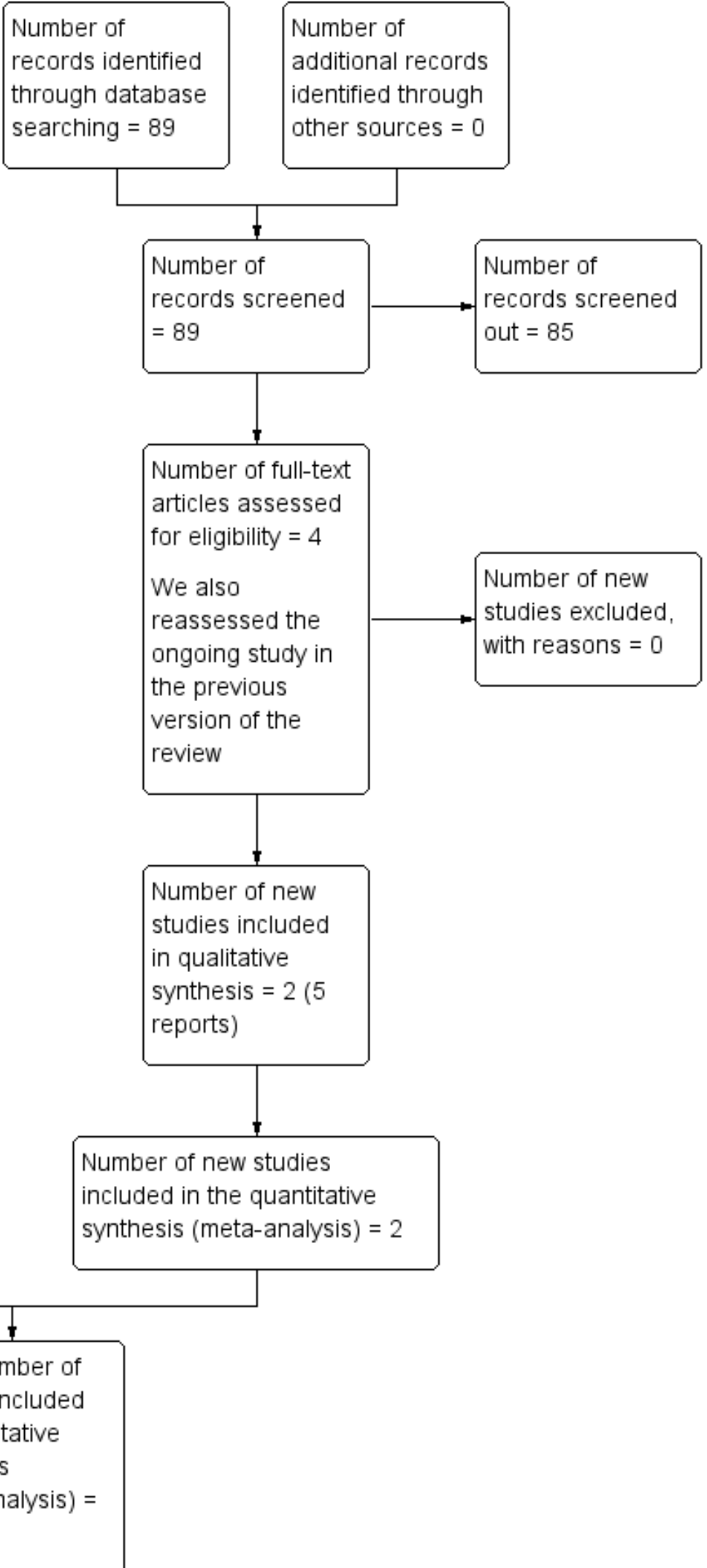


We assessed four new trial reports and also reassessed one ongoing study. We included two new trials in five reports (Duvekot 2015; Vigil-De Gracia 2013).

We included four trials in the previous version of this review (Mesbah 2003; Odendaal 1990; Sibai 1994; Thornton 2004 (GRIT)).

\section{Included studies}

We included six trials with a total of 748 women in this review.

The Thornton 2004 (GRIT) trial contributed 262 participants to this review, which is just under half of the participants recruited to this trial, which compared management strategies for women with a growth restricted fetus. The study was jointly funded by the UK Medical Research Council (MRC), the European Union Concerted Action, and the Dutch Princess Beatrix Foundation. There were no declarations of interest, and it took place from November 1993 to March 2001. The most recent study was the largest, with 267 women randomised; it was conducted between August 2010 and August 2012 (Vigil-De Gracia 2013). This trial was carried out in Latin America, and was funded by the Marjorie Milham Research Fund, Pennsylvania Hospital, Perelman School of Medicine, University of Pennsylvannia. The trial only recruited women between 28 and 33 weeks' gestation. Participants below 28 weeks were excluded, because it was felt that the neonatal care provided was too poor, due to limited resources in some units, which may have restricted generalisablity. There were no declarations of interest by the researchers. The study by Mesbah and colleagues recruited women between January 2001 and May 2002. The funding sources were not disclosed and there were no statements about declarations of interest. The study was judged to be at high risk of bias due to missing outcome data (Mesbah 2003). The oldest of the trials was by Odendaal, and published in 1990 (Odendaal 1990). Recruitment took place between January 1986 and January 1988. The study was carried out in South Africa, and funded by the South African Medical Research Council. There were no declarations of interest made by the researchers. The fifth trial was carried out in the USA (Sibai 1994). The trial recruited 95 women from January 1991 to July 1993. The funding source was not stated, and there were no declarations of interest. The sixth trial was conducted in the Netherlands, in 2015 , and has only been reported as a poster. No further details were obtained from the authors (Duvekot 2015).

\section{Setting}

Three trials were multi-centre: one was UK based and involved 69 hospitals in 13 European countries (Thornton 2004 (GRIT)), one was based in Latin America, and was carried out in eight tertiary hospitals in Latin America (Vigil-De Gracia 2013), and a third was based in nine hospitals in the Netherlands (Duvekot 2015). The other three trials were single-centre trials, based in Egypt (Mesbah 2003), South Africa (Odendaal 1990), and the USA (Sibai 1994).

\section{Participants}

One trial included 548 pregnant women with fetal growth restriction, between 24 and 36 weeks' gestation, an umbilical artery Doppler waveform recorded and clinical uncertainty about whether immediate delivery was indicated (Thornton 2004 (GRIT)). We included a subset of women from this trial, who were at less than or equal to 34 weeks' gestation $(\mathrm{N}=262)$, and had severe pre-eclampsia. Vigil-De Gracia 2013 included 267 women who had severe pre-eclampsia, and were between 28 and 33 weeks' gestation. Women with the condition, who were at less that 28 weeks' gestation were excluded from this trial. Mesbah 2003 included 30 women with severe pre-eclampsia between 28 and 33 weeks' gestation; Odendaal 1990 included 38 women with severe pre-eclampsia between 28 and 34 weeks' gestation; and Sibai 1994 included 95 women with severe pre-eclampsia at 28 to 32 weeks' gestation. In four trials, it was explicitly stated that women with an immediate indication for delivery in the maternal or fetal interest were excluded (Mesbah 2003; Odendaal 1990; Sibai 1994; Vigil-De Gracia 2013). In one trial, this exclusion was implicit, since the trial entry criterion was obstetrician uncertainty about the benefit of immediate or delayed delivery (Thornton 2004 (GRIT)). One trial included 56 women between 28 and 34 weeks of gestation with severe pre-eclampsia, with or without HELLP (haemolysis, elevated liver enzymes and low platelets) syndrome (Duvekot 2015). The trial stopped early due to poor recruitment.

\section{Interventions}

In five trials, women had a 24- to 48-hour period of stabilisation, during which they were given steroids to accelerate fetal lung maturity, and if necessary, magnesium sulphate to prevent seizures, and antihypertensives to lower blood pressure. If they continued to meet the eligibility criteria at the end of this period, they were then randomised. They were either randomised to the interventionist group, which involved immediate delivery by caesarean section or induction, or to the expectant management group, who were managed with hospitalisation and intensive maternal and fetal monitoring. Earlier delivery in this expectant group was implemented if either the maternal or fetal condition deteriorated, as determined by prespecified criteria. In one trial, women in the intervention group were delivered immediately, and the control group were given temporising management (Duvekot 2015).

\section{Outcomes}

The main outcomes in all studies included maternal, perinatal, and neonatal morbidity and mortality outcomes. Only one trial included long-term outcomes; measures of long-term growth and development at two years (Thornton 2004 (GRIT)).

For further details see Characteristics of included studies.

\section{Excluded studies}

We excluded two trials as they did not meet the inclusion criteria of the review (Gruppo di Studio1998; Langenveld 2011). In both trials, the women did not have severe pre-eclampsia.

See table of Characteristics of excluded studies.

\section{Risk of bias in included studies}

Overall, we judged three trials to be at low risk of bias (Sibai 1994; Thornton 2004 (GRIT); Vigil-De Gracia 2013), two were unclear (Duvekot 2015; Odendaal 1990), and one was at high risk of bias (Mesbah 2003).

See Figure 2 and Figure 3 for summaries of 'Risk of bias' assessment. 
Figure 2. 'Risk of bias' graph: review authors' judgements about each risk of bias item, presented as percentages across all included studies

Random sequence generation (selection bias)

Allocation concealment (selection bias)

Blinding of participants and personnel (performance bias)

Blinding of outcome assessment (detection bias)

Incomplete outcome data (attrition bias)

Selective reporting (reporting bias)

Other bias

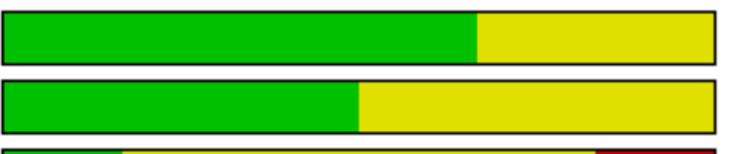

L
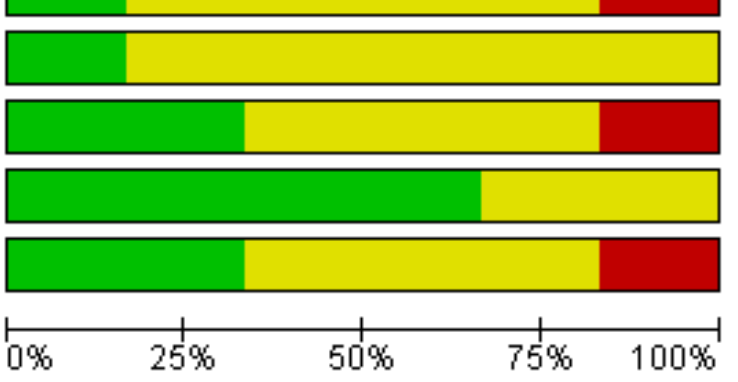

Low risk of bias

Unclear risk of bias

High risk of bias 
Figure 3. 'Risk of bias' summary: review authors' judgements about each risk of bias item for each included study

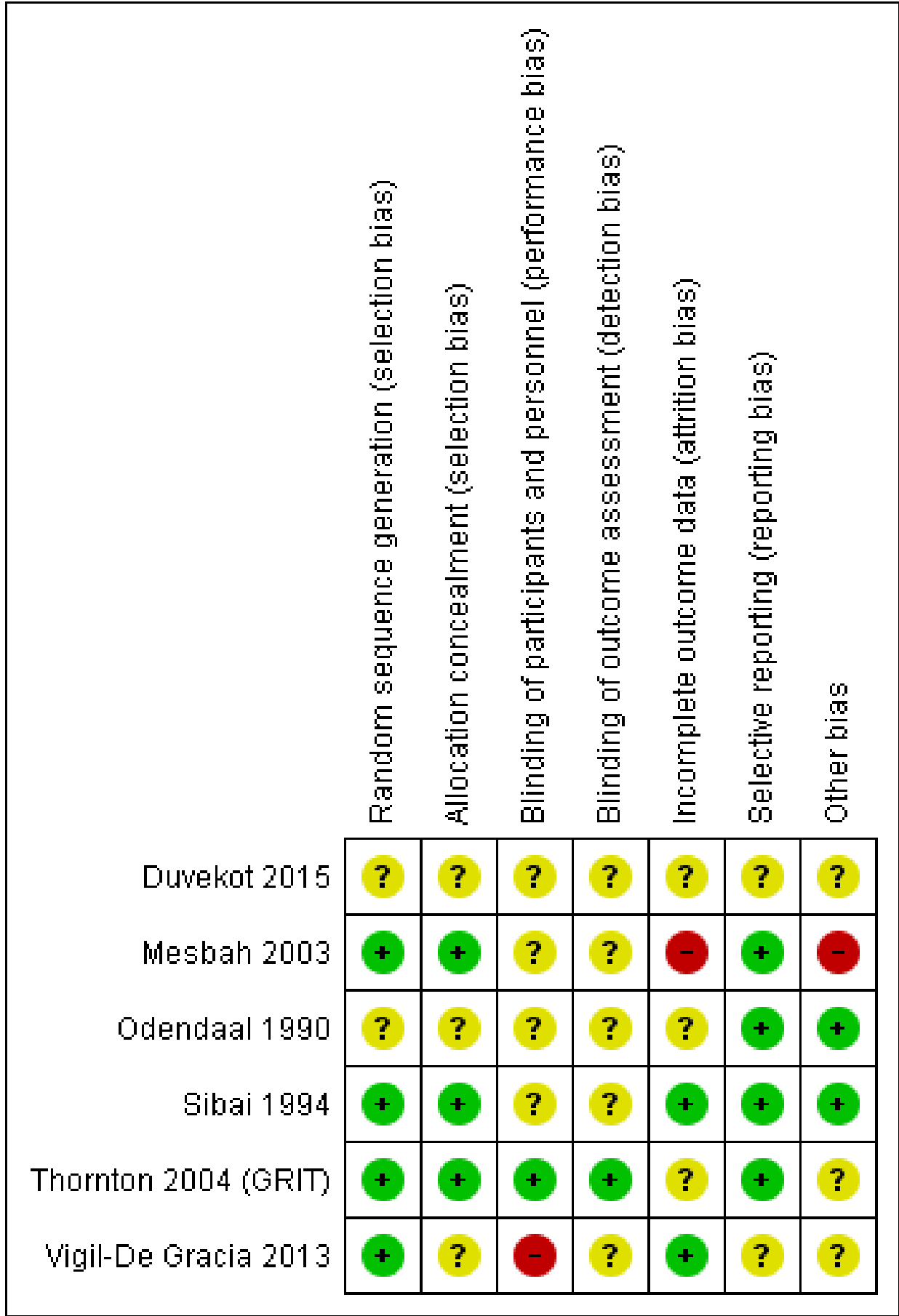

\section{Allocation}

In two studies, the methods used for randomisation and concealment of allocation were not described (Duvekot 2015; Odendaal 1990); in another, the description of concealment of allocation was unclear, and we were uncertain if this was adequate (Vigil-De Gracia 2013), and in the other three trials, the methods of both randomisation and concealment were adequate (Mesbah 2003; Sibai 1994; Thornton 2004 (GRIT)).

\section{Blinding}

Blinding of participants, personnel, or outcome assessors was not described in four of the trials (Duvekot 2015; Mesbah 2003; Odendaal 1990; Sibai 1994). One study was described as open label and recognised that the outcomes were not concealed (VigilDe Gracia 2013). Blinding of outcome assessment for long-term outcomes, such as Griffiths assessment, was reported in one trial (Thornton 2004 (GRIT)). 


\section{Incomplete outcome data}

In two trials, all women appeared to have been accounted for in the results (Sibai 1994; Vigil-De Gracia 2013). In one trial, individual patient data for a subset of women with severe pre-eclampsia were provided by the authors of the original trial, and it was not possible to tell how complete this dataset was (Thornton 2004 (GRIT)). In another trial, it was not clear, from the results tables, how many were included in the analyses (Odendaal 1990). In Duvekot 2015, it stated that analysis was by intention-to-treat, and numbers randomised appeared to be accounted for in the analyses, but the trial was stopped early because of low recruitment. In one trial, 41 women were recruited, but 11 (27\%) were judged to be too compromised for expectant management, and were delivered by caesarean section; and after randomisation, five patients appear to be missing from the results table 2 (Mesbah 2003).

\section{Selective reporting}

All expected outcomes appear to have been reported in four trials (Mesbah 2003; Odendaal 1990; Sibai 1994; Thornton 2004 (GRIT)). In one trial, some of the outcomes reported in the trial registry record and protocol were not reported, but this was probably due to the trial stopping early, rather than selective reporting (Duvekot 2015). In one trial, the trial was registered, however the planned secondary outcomes were listed only as 'Perinatal complications and maternal complications' (Vigil-De Gracia 2013).

\section{Other potential sources of bias}

In two studies, baseline characteristics were similar between groups and no other sources of bias were apparent (Odendaal 1990; Sibai 1994). In one study, other bias may have been introduced, as only a subset of the original randomised sample provided data for analysis, but this was not clear (Thornton 2004 (GRIT)). In one study, the severe group was excluded from the study, and no baseline characteristics were described for this group of patients (Mesbah 2003). In one study, three women in the expectant management group were excluded from the analyses. Two women refused to remain in hospital, and one woman received incorrect treatment due to physician error in Vigil-De Gracia 2013. In one study, the trial stopped early due to low recruitment (Duvekot 2015).

\section{Effects of interventions}

See: Summary of findings for the main comparison Interventionist care compared to expectant (delayed delivery) care for severe pre-eclampsia for severe pre-eclampsia between 24 and 34 weeks' gestation

\section{Interventionist care versus expectant (delayed delivery) care for severe pre-eclampsia}

\section{Primary outcomes}

Three studies (415 women) reported on primary outcomes of relevance to the woman. Two studies reported on maternal death, and there were no maternal deaths in either study (0/159 vs 0/161; effect not estimable; two studies, 320 women; low-quality evidence; Analysis 1.1). Due to very low-quality evidence from two studies, it was unclear whether interventionist care reduced eclampsia (risk ratio (RR) $0.98,95 \%$ confidence interval $(\mathrm{Cl}) 0.06$ to 15.58; two studies, 359 women; Analysis 1.2), or pulmonary oedema (RR 0.45, 95\% Cl 0.07 to 3.00; two studies, 415 women; Analysis 1.3).
Low-quality evidence from two studies suggested little or no clear difference between the interventionist and expectant care groups for HELLP syndrome (RR 1.09, 95\% $\mathrm{Cl} 0.62$ to 1.91; two studies, 359 women; Analysis 1.4). Stroke was not an outcome reported in any trial.

For the baby, there was insufficient evidence for any reliable conclusions about the effects on stillbirth (RR $0.30,95 \% \mathrm{Cl} 0.07$ to 1.23; five trials; 692 women, with 700 babies), perinatal death (RR 1.11, 95\% Cl 0.62 to 1.99; three studies, 343 infants; lowquality evidence), or neonatal death after delivery (RR 1.32, 95\% $\mathrm{Cl} 0.80$ to 2.19; five trials; 485 babies; Analysis 1.6. More babies whose mothers had been allocated to the interventionist group had intraventricular haemorrhage (RR $1.94,95 \% \mathrm{Cl} 1.15$ to 3.29; two trials; 537 women; moderate-quality evidence; Analysis 1.7).

\section{Secondary outcomes}

Women allocated to the interventionist group were no more likely to have a caesarean section than those allocated to an expectant policy (random-effects, average RR $1.01,95 \% \mathrm{Cl} 0.91$ to 1.12 ; heterogeneity: $\mathrm{Tau}^{2}=0.01, \mathrm{I}^{2}=63 \%$; six trials; 745 women; Analysis 1.8). There were no clear differences between the two management strategies for renal failure (RR $0.32,95 \% \mathrm{Cl} 0.05$ to 1.99 ; three trials; 397 women; Analysis 1.9), or placental abruption (RR $0.42,95 \% \mathrm{Cl}$ 0.18 to 0.96 ; four trials; 453 women; Analysis 1.10). Liver failure, cardiac arrest, and the need for invasive monitoring for the woman were not reported in any of the trials.

This review suggested that an interventionist policy of care may be associated with increased morbidity for the baby. For example, those babies whose mothers had been allocated to the interventionist group had more hyaline membrane disease (RR 2.30, $95 \% \mathrm{Cl} 1.39$ to 3.81; two trials; 133 women; Analysis 1.11), were more likely to require ventilation (RR $1.50,95 \% \mathrm{Cl} 1.11$ to 2.02 ; two trials; 300 women; Analysis 1.12), and had a lower gestation at birth (random-effects, mean difference (MD) -9.91 days, 95\% Cl -16.37 to -3.45 days; heterogeneity: Tau $^{2}=31.74, I^{2}=76 \%$; four trials; 425 women; Analysis 1.13). There was no clear difference between the allocated groups in the risk of developing necrotising enterocolitis, (RR 1.79, $95 \% \mathrm{Cl} 0.84$ to 3.81 ; four trials; 670 women; Analysis 1.14). Babies whose mothers had been allocated to the interventionist policy were less likely to be small-for-gestational age (RR $0.38,95 \% \mathrm{Cl} 0.24$ to 0.61 ; three trials; 400 women; Analysis 1.15). In one trial (262 women), there were no clear differences between the two management strategies for low Apgar score at five minutes (Analysis 1.16), neonatal seizures (Analysis 1.17), and three measures of long-term growth and development; cerebral palsy (Analysis 1.18), poor hearing, use of hearing aid (Analysis 1.19), and impaired vision (Analysis 1.20).

Babies whose mothers had been allocated to the interventionist group were no more likely to be admitted to neonatal intensive care than the expectant management group (average RR 1.19, 95\% $\mathrm{Cl} 0.89$ to 1.60 ; heterogeneity: $\mathrm{Tau}^{2}=0.05 ; \mathrm{I}^{2}=84 \%$; three trials, 400 women Analysis 1.21), or have a longer stay in the neonatal intensive care unit (random-effects, MD -7.38 days, $95 \% \mathrm{Cl}-0.45$ to 15.20 days; heterogeneity: Tau $^{2}=40.93, \mathrm{I}^{2}=85 \%$; three trials, 400 women; Analysis 1.22), than those allocated to receive an expectant policy. Other outcomes on the use of health service resources were not reported in any of the trials (need for intensive care for the woman; need for high-dependency care or observation, or both, for the woman; surfactant for the baby). 


\section{DISCUSSION}

Timing the delivery of a very premature infant in the presence of severe pre-eclampsia is a difficult clinical decision. When the mother's life is in danger, there is no doubt that delivery is the only correct course of action. This situation is rare. More frequently, if the pregnancy is continued, the risks of maternal morbidity or intrauterine fetal demise have to be constantly balanced against the hazards of prematurity to the fetus if delivered. Most obstetricians would probably be cautious, and expedite delivery in favour of the outcome for the mother, and the guarantee of a live baby at delivery. What is not clear, is to what level, if at all, this adversely affects the baby.

Only the GRIT study prespecified fetal assessment parameters as entry criteria into the trial (Thornton 2004 (GRIT)). The other studies used fetal assessment to trigger delivery if there was evidence of significant compromise. Therefore, it is not possible to compare the trials for the condition of the fetuses on trial entry. However, it is unlikely that there would have been any clinical differences where this was not formally assessed at trial entry. If there were signs of imminent fetal demise, then the women would not have been randomised into the trials. But there is the potential for unseen bias, and future trials must include a formal assessment of fetal well-being on trial entry.

Currently, there were insufficient data to justify any of our prespecified subgroup analyses. These will be included in future updates of this review, when larger trials become available.

There were insufficient data for reliable conclusions from this review. However, the evidence suggests that short-term morbidity for the baby may be reduced by a policy of expectant care. This is perhaps surprising, given that expectant management increases the length of time a fetus is exposed to severe pre-eclampsia, with the potential to adversely affect fetal growth and well-being. In fact, this is often stated as a reason for intervention. The results of this review suggested this may be otherwise. While the babies in the expectant management group were smaller, their short-term outcomes were better. Before this policy can be recommended in clinical practice, further evidence is required to demonstrate whether there is truly a short-term benefit for the baby without any increase in mortality, and if so, that it continues in the longer term. Reassurance is also needed that there is no increase in morbidity for the mother.

\section{Summary of main results}

There was insufficient evidence on stillbirth or death after delivery to draw reliable conclusions about the effects of either policy for care. However, there was some evidence from this review to suggest that a policy of prolonging pregnancy reduced serious morbidity in the neonatal period of life. Fewer babies had an intraventricular haemorrhage or hyaline membrane disease, and there were reduced levels of ventilation for those allocated to expectant management. Babies whose mothers were allocated to expectant care were no more likely to be admitted to the neonatal intensive care unit, and when admitted, were more likely to stay there for shorter periods of time. There were insufficient data to draw any conclusions about the comparative effects of these two policies of care on the mothers' health. Even taken together, these studies did not have sufficient sample size to demonstrate small to moderate differences in maternal outcome.

\section{Overall completeness and applicability of evidence}

There was insufficient evidence from this review to recommend a particular management policy for this area of obstetric care. The numbers of participants in the trials was too small to be able to demonstrate differences in most significant (primary) outcomes, and where differences were found, there was a considerable level of heterogeneity, or the contribution was mainly from one trial. The same was true for the analysis of the secondary outcome measures.

\section{Quality of the evidence}

We judged three of the trials included in the review to be at unclear risk of both performance and detection bias. It was not possible to blind personnel and participants to interventions, but most outcomes were objective outcomes, and were unlikely to be affected by blinding, e.g. death, eclampsia. One study was also judged to be at risk of attrition bias (Mesbah 2003). The Thornton 2004 (GRIT) trial was not originally designed to examine severe pre-eclampsia. It looked at interventionist versus expectant management for babies with growth restriction. A by-product of this study, was that a subset of women also had severe preeclampsia, and it was these women who we included in the review. Overall, we judged three trials to have a low risk of bias (Sibai 1994; Thornton 2004 (GRIT); Vigil-De Gracia 2013), two as unclear (Duvekot 2015; Odendaal 1990), and one at a high risk of bias (Mesbah 2003).

We also assessed the quality of the evidence for seven key maternal and baby outcomes, using the GRADE approach (see Summary of findings for the main comparison). For eclampsia and pulmonary oedema, we judged the evidence to be very lowquality, downgraded due to concerns relating to limitations in study design and imprecision, due to small sample sizes, small number of events, and wide confidence intervals crossing the line of no effect. For maternal death, HELLP (haemolysis, elevated liver enzymes and low platelets) syndrome, and perinatal mortality, we judged the evidence to be low-quality, due again to limitations in study design and imprecision. We judged the evidence for one outcome, intraventricular haemorrhage or hypoxic ischaemic encephalopathy, to be of moderate quality, downgraded due to limitations in study design.

\section{Potential biases in the review process}

We took steps to minimise bias, although we are aware that bias may be present in our review. Two review authors independently assessed studies for eligibility and extracted the data as necessary. We resolved discrepancies through discussion, or if required, we consulted a third review author. Two review authors also independently performed GRADE assessments, and resolved discrepancies though discussion. One of the review authors ( $\mathrm{J}$ Thornton) was the Principle Investigator for one of the included trials (Thornton 2004 (GRIT)). To remove the potential for bias, the GRIT trial data were supplied directly to two other review authors from the trial statistician. J Thornton had no dealings with the acquisition, preparation, or analysis of the GRIT trial data in this review.

\section{Agreements and disagreements with other studies or reviews}

There were no other systematic reviews of delivery timing in pregnancies complicated by pre-eclampsia before 34 weeks. 
However, our findings were consistent with the recommendations of all the expert guidelines reviewed by Gillon 2014, which all recommend expectant management before 34 weeks, in the absence of uncontrollable hypertension, maternal organ failure, or severe fetal compromise.

\section{AUTHORS' CONCLUSIONS}

\section{Implications for practice}

These data were insufficient to reach any firm conclusions about the comparative effects of these alternative strategies for the care of women with severe, early onset pre-eclampsia, in the absence of an over-riding maternal or fetal indication for delivery. Nevertheless, the apparent increase in some measures of neonatal morbidity associated with interventionist care suggested that early delivery would need to be justified by a realistic expectation of harm to the mother if the pregnancy was continued. The current advice from both the National Insitute for Clinical Excellence and the World Health Organization seems to reflect this interpretation of the evidence to date, as both recommend deferring delivery until there are clear signs of fetal compromise, inability to control the maternal blood pressure, or evidence of maternal organ failure (NICE 2010; WHO 2011).

\section{Implications for research}

Larger trials are needed to confirm whether the benefits for the child associated with a policy of expectant care are real, and without significant risks, and to provide reassurance that there is no increase in risk of morbidity or mortality for the mother.

\section{ACK N O WLEDGEMENTS}

The National Institute for Health Research (NIHR) is the largest single funder of the Cochrane Pregnancy and Childbirth Group. The views and opinions expressed therein are those of the authors and do not necessarily reflect those of the NIHR, NHS or the Department of Health.

We thank Leanne Jones for her contribution as an author in the previous update (Churchill 2013), and Leanne Jones and Anna Cuthbert for preparing the GRADE 'Summary of findings' table for this update. 
R E F E R E N C E S

\section{References to studies included in this review}

Duvekot 2015 \{published data only\}

* Duvekot J, Bax C, Bloemenkamp K, Dijk P, Van D, Franssen M, et al. Temporizing management versus termination of pregnancy in women with severe preeclampsia at 28-34 weeks (TOTEM-Trial). American Journal of Obstetrics and Gynecology 2015;212(1 Suppl 1):S246.

Duvekot JJ, Steegers EAP, Hop WCJ, Franx A, van der Post JAM, van Wassenaer $A$, et al. TOTEM study (temporise or terminate pregnancy in women with severe preeclampsia at 28-34 weeks): a study protocol. Pregnancy Hypertension 2011;1 Suppl 1:295.

NTR2986. Expectant or active management in women with severe preeclampsia at 28-34 weeks. Available at trialregister.nl/ trialreg/admin/rctview.asp?TC=2986 (first received 11 July 2011).

\section{Mesbah 2003 \{published data only\}}

Mesbah EMM. Severe preterm preeclampsia: aggressive or expectant management?. Medical Journal of Cairo University 2003;71(1):175-82

\section{Odendaal 1990 \{published data only\}}

Odendaal HJ, Pattinson RC. Active or conservative treatment of severe preeclampsia - a randomized control trial. Proceedings of 37th Annual Meeting of the Society for Gynecologic Investigation; 1990 March 21-24; St Louis, USA. 1990:359.

* Odendaal HJ, Pattinson RC, Bam R, Grove D, Kotze TJ. Aggressive or expectant management for patients with severe preeclampsia between 28-34 weeks' gestation: a randomized controlled trial. Obstetrics \& Gynecology 1990;76:1070-5.

\section{Sibai 1994 \{published data only\}}

Sibai BM, Mercer BM, Schiff E, Friedman SA. Aggressive versus expectant management of severe preeclampsia at 28 to 32 weeks' gestation: a randomized controlled trial. American Journal of Obstetrics and Gynecology 1994;171:818-22.

\section{Thornton 2004 (GRIT) \{published data only\}}

GRIT Study Group. A randomised trial of timed delivery for the compromised preterm fetus: short term outcomes and Bayesian interpretation. BJOG: An International Journal of Obstetrics and Gynaecology 2003;110:27-32.

Hornbuckle J, Thornton JG, Vail A, GRIT SG. The Growth Restriction Intervention Trial (GRIT): interim progress report. Women's Health - into the new millennium. Proceedings of the 4th International Scientific Meeting of the Royal College of Obstetricians and Gynaecologists; 1999 October 3-6; Cape Town South Africa. RCOG, 1999:76.

Schneider KTM, Brocker J, Thornton J. A randomised intervention of timed delivery for the compromised preterm fetus [Randomisierte Intervention zur Optimierung des Entbindungszeitpunktes bei kompromittierten IUGR-Feten (Euro-GRIT)]. Geburtshilfe und Frauenheilkunde 2000;60 Suppl 1:S72.
* Thornton JG, Hornbuckle J, Vail A, Spiegelhalter DJ, Levene M, GRIT study group. Infant wellbeing at 2 years of age in the Growth Restriction Intervention Trial (GRIT): multicentred randomised controlled trial. Lancet 2004;364:513-20.

Walker DM, Marlow N, Upstone L, Gross H, Hornbuckle J, Vail A, et al. The Growth Restriction Intervention Trial: longterm outcomes in a randomized trial of timing of delivery in fetal growth restriction. American Journal of Obstetrics and Gynecology 2011;204(1):34.e1-9.

\section{Vigil-De Gracia 2013 \{published data only\}}

NCT01164852. Expectant management of severe preeclampsia at 28 to 33 week's gestation: a randomized controlled trial. Available at clinicaltrials.gov/ct2/show/NCT01164852 (first received 19 July 2010).

* Vigil-De Gracia P, Reyes Tejada O, Calle Minaca A, Tellez G, Chon VY, Herrarte E, et al. Expectant management of severe preeclampsia remote from term: the MEXPRE Latin Study, a randomized, multicenter clinical trial. American Journal of Obstetrics and Gynecology 2013;209(5):425.e1-8.

\section{References to studies excluded from this review}

Gruppo di Studio1998 \{published data only\}

Gruppo di Studio Ipertensione in Gravidanza. Nifedipine versus expectant management in mild to moderate hypertension in pregnancy. British Journal of Obstetrics and Gynaecology 1998;105:718-22.

\section{Langenveld 2011 \{published data only\}}

Langenveld J, Broekhuijsen K, van Baaren GJ, van Pampus MG, van Kaam AH, Groen H, et al. Induction of labour versus expectant monitoring for gestational hypertension or mild preeclampsia between 34 and 37 weeks' gestation (HYPITAT-II): A multicentre, open-label randomised controlled trial. $B M C$ Pregnancy and Childbirth 2011;11:50.

\section{Additional references}

\section{Brown 2001}

Brown MA, Lindheimer MD, de Swiet M, van Assche A, Moutquin J-M. The classification and diagnosis of the hypertensive disorders of pregnancy: statement from the International Society for the Study of Hypertension in Pregnancy. Hypertension in Pregnancy 2001;20:ix-xiv.

\section{Crowley 1996}

Crowley P. Prophylactic corticosteroids for preterm birth. Cochrane Database of Systematic Reviews 1996, Issue 1. [DOI: 10.1002/14651858.CD000065.pub2]

\section{Davey 1988}

Davey DA, MacGillivray I. The classification and definition of the hypertensive disorders in pregnancy. American Journal of Obstetrics and Gynecology 1988;158:892-8. 


\section{Derham 1989}

Derham RJ, Hawkins DF, deVries LS, Aber VR, Elder MG. Outcome of pregnancies complicated by severe hypertension and delivered before 34 weeks: stepwise logistic regression analysis of prognostic factors. British Journal of Obstetrics and Gynaecology 1989;96:1173-81.

\section{Duley 1999a}

Duley L, Henderson-Smart D. Reduced salt intake compared to normal dietary salt, or high intake, in pregnancy.

Cochrane Database of Systematic Reviews 1999, Issue 3. [DOI: 10.1002/14651858.CD001687]

\section{Duley 1999b}

Duley L, Williams J, Henderson-Smart DJ. Plasma volume expansion for treatment of pre-eclampsia. Cochrane Database of Systematic Reviews 1999, Issue 4. [DOI: 10.1002/14651858.CD001805]

\section{Duley 2005}

Duley L, Henderson-Smart D, Meher S. Altered dietary salt for preventing pre-eclampsia, and its complications. Cochrane Database of Systematic Reviews 2005, Issue 4. [DOI: 10.1002/14651858.CD005548]

\section{Duley 2007}

Duley L, Henderson-Smart DJ, Meher S, King JF. Antiplatelet agents for preventing pre-eclampsia and its complications. Cochrane Database of Systematic Reviews 2007, Issue 2. [DOI: 10.1002/14651858.CD004659.pub2]

\section{Duley 2009}

Duley L, Henderson-Smart DJ, Walker GJA. Interventions for treating pre-eclampsia and its consequences: generic protocol. Cochrane Database of Systematic Reviews 2009, Issue 2. [DOI: 10.1002/14651858.CD007756]

\section{Duley 2010}

Duley L, Gülmezoglu AM, Henderson-Smart DJ, Chou D. Magnesium sulphate and other anticonvulsants for women with pre-eclampsia. Cochrane Database of Systematic Reviews 2010, Issue 11. [DOI: 10.1002/14651858.CD000025.pub2]

\section{Duley 2013}

Duley L, Meher S, Jones L. Drugs for treatment of very high blood pressure during pregnancy. Cochrane Database of Systematic Reviews 2013, Issue 7. [DOI: 10.1002/14651858.CD001449.pub3]

\section{Gillon 2014}

Tessa ER, Gillon TER, Pels A, Von Dadleszen P, MacDonell K, Magee L. Hypertensive disorders of pregnancy: a systematic review of international clinical practice guidelines. PLOS ONE 1 December 2014;9:e113715.

\section{GRADE Handbook}

Schünemann H, Brożek J, Guyatt G, Oxman A, editor(s). Handbook for grading the quality of evidence and the strength of recommendations using the GRADE approach (updated October 2013). GRADE Working Group, 2013. Available from gdt.guidelinedevelopment.org/app/handbook/handbook.html.

\section{GRADEpro GDT [Computer program]}

McMaster University (developed by Evidence Prime). GRADEpro GDT. Version accessed prior to 25 September 2018. Hamilton

(ON): McMaster University (developed by Evidence Prime), 2015.

\section{Higgins 2011}

Higgins JPT, Green S, editor(s). Cochrane Handbook for Systematic Reviews of Interventions Version 5.1.0 (updated March 2011). The Cochrane Collaboration, 2011. Available from handbook.cochrane.org.

\section{Hofmeyr 2014}

Hofmeyr GJ, Lawrie TA, Atallah ÁN, Duley L, Torloni MR. Calcium supplementation during pregnancy for preventing hypertensive disorders and related problems. Cochrane Database of Systematic Reviews 2014, Issue 6. [DOI: 10.1002/14651858.CD001059.pub4]

\section{Magee 2009}

Magee LA, Yong PJ, Espinosa V, Cote AM, Chen I, von Dadelszen P. Expectant management of severe preeclampsia remote from term: a structured systematic review. Hypertension in Pregnancy 2009;28(3):312-47.

\section{Makrides 2014}

Makrides M, Crosby DD, Bain E, Crowther CA. Magnesium supplementation in pregnancy. Cochrane Database of Systematic Reviews 2014, Issue 4. [DOI: 10.1002/14651858.CD000937.pub2]

\section{Morris 2012}

Morris RK, Riley RD, Doug M, Deeks JJ, Kilby MD. Diagnostic accuracy of spot urinary protein and albumin to creatinine ratios for detection of significant proteinuria or adverse pregnancy outcome in patients with suspected pre-eclampsia: systematic review and meta-analysis. BMJ (Clinical research ed.) 2012;345:e4342. [PUBMED: 22777026]

\section{NICE 2010}

National Collaborating Centre for Women's and Children's Health. Hypertension in pregnancy: the management of hypertensive disorders during pregnancy (NICE Clinical Guidelines, No. 107). London: RCOG Press, 2010.

\section{RevMan 2014 [Computer program]}

Nordic Cochrane Centre, The Cochrane Collaboration. Review Manager 5 (RevMan 5). Version 5.3. Copenhagen: Nordic Cochrane Centre, The Cochrane Collaboration, 2014.

\section{Roberts 2013}

Roberts D, Brown J, Medley N, Dalziel SR. Antenatal corticosteroids for accelerating fetal lung maturation for women at risk of preterm birth. Cochrane Database of Systematic Reviews 2017, Issue 3. [DOI: 10.1002/14651858.CD004454.pub3]

\section{Sibai 1984}

Sibai BM, Spinnato JA, Watson DL, Hill GA, Anderson GD. Pregnancy outcome in 303 cases with severe preeclampsia. Obstetrics \& Gynecology 1984;64:319-25. 


\section{von Dadelszen 2011}

von Dadelszen P, Payne B, Li J, Ansermino MJ, Broughton FP, Cote $\mathrm{A}$, et al. Prediction of adverse maternal outcomes in preeclampsia: development and validation of the full PIERS model. Lancet 2011;377(9761):219-27.

\section{WHO 2011}

World Health Organization. WHO recommendations for prevention and treatment of pre-eclampsia and eclampsia. www.who.int/reproductivehealth/publications/maternal_ perinatal_health/9789241548335/en/ 2011:1-48.

\section{References to other published versions of this review}

\section{Churchill 2002}

Churchill D, Duley L. Interventionist versus expectant care for severe pre-eclampsia before term. Cochrane

\section{CHARACTERISTICS OF STUDIES}

Characteristics of included studies [ordered by study ID]
Database of Systematic Reviews 2002, Issue 3. [DOI: 10.1002/14651858.CD003106]

\section{Churchill 2013}

Churchill D, Duley L, Thornton JG, Jones L. Interventionist versus expectant care for severe pre-eclampsia between 24 and 34 weeks' gestation. Cochrane Database of Systematic Reviews 2013, Issue 7. [DOI: 10.1002/14651858.CD003106.pub2]

\section{Duley 1995}

Duley L. Aggressive vs expectant management of pre-eclampsia. In: Keirse MJNC, Renfrew MJ, Neilson JP, Crowther C, editor(s). Pregnancy and Childbirth Module. In: The Cochrane Database of Systematic Reviews (database on disk and CDROM). The Cochrane Collaboration; Issue 2, Oxford: Update Software; 1995.

* Indicates the major publication for the study

Duvekot 2015

\begin{tabular}{ll} 
Methods & Multi-centre randomised controlled trial \\
& Setting: 19 hospitals in the Netherlands \\
\hline Participants & 56 women from nine hospitals were randomised. \\
& $\begin{array}{l}\text { Inclusion criteria: Women between } 28+0 \text { and } 34+0 \text { weeks of gestation after admission for severe pre- } \\
\text { eclampsia with or without HELLP syndrome }\end{array}$
\end{tabular}

Interventions Immediate delivery $(\mathrm{N}=26)$ : delivery 48 hours after admission

Expectant management $(\mathrm{N}=30)$ : described as 'temporising management'

Outcomes Primary outcome: composite major maternal and neonatal morbidity and mortality; maternal longterm outcome defined as persistent morbidity

Women: median prolongation of labour; maternal death; pulmonary edema; placental abruption, encephalopathy or eclampsia, ARDS (Acute Respiratory Distress Syndrome), cerebrovascular incident, liver haematoma or liver rupture, acute fatty liver of pregnancy, severe renal insufficiency, thromboembolism

Baby: neonatal morbidity; neonatal death; birthweight; long-term neonatal outcome using Bailey-3 assessment

Notes The trial closed after 24 months because of low recruitment. Power analysis estimated 1130 women needed to rule out an increase in adverse perinatal outcome, with at most 5\%

Dates of the study: June 2011 to June 2013

Funding sources: Erasmus Medical Center

Declarations of interest: none mentioned

\section{Risk of bias}

Bias Authors' judgement Support for judgement


Duvekot 2015 (Continued)

Random sequence genera- Unclear risk No details on method for sequence generation in abstract presented at poster tion (selection bias) session

\begin{tabular}{|c|c|c|}
\hline $\begin{array}{l}\text { Allocation concealment } \\
\text { (selection bias) }\end{array}$ & Unclear risk & $\begin{array}{l}\text { No details on method of allocation concealment in abstract presented at } \\
\text { poster session }\end{array}$ \\
\hline
\end{tabular}

Blinding of participants Unclear risk No details on blinding in abstract presented at poster session

and personnel (perfor-

mance bias)

All outcomes

\begin{tabular}{lll}
\hline $\begin{array}{l}\text { Blinding of outcome as- } \\
\text { sessment (detection bias) } \\
\text { All outcomes }\end{array}$ & Unclear risk & No details on blinding in abstract presented at poster session \\
\hline $\begin{array}{l}\text { Incomplete outcome data } \\
\text { (attrition bias) } \\
\text { All outcomes }\end{array}$ & Unclear risk & $\begin{array}{l}\text { States that analysis was by intention-to-treat and numbers randomised ap- } \\
\text { peared to be accounted for in analyses }\end{array}$ \\
\hline $\begin{array}{l}\text { Selective reporting (re- } \\
\text { porting bias) }\end{array}$ & Unclear risk & $\begin{array}{l}\text { Difficult to tell, because some of the outcomes reported in the trial registry } \\
\text { record and protocol were not reported in the abstract, but probably due to the } \\
\text { trial stopping early, and so many of the outcomes may not have been report- } \\
\text { ed, rather than selectively reported. }\end{array}$ \\
\hline
\end{tabular}

Other bias Unclear risk The trials was stopped early because of low recruitment.

\section{Mesbah 2003}

$\begin{array}{ll}\text { Methods } & \text { Randomisation was generated from a random number sequence table. Blind allocation was made us- } \\ \text { ing consecutively sealed envelopes. Odd numbers = aggressive management, even numbers = expec- } \\ \text { tant management. Analysis was by ITT. Follow-up was judged to be } 100 \% .\end{array}$

Participants

30 pregnant women with severe PE between 28 and $33+6$ days gestation. Severe PE was defined as a $\mathrm{BP}>180 / 120 \mathrm{mmHg}$ on 2 occasions, 30 minutes apart; or a BP between 160 to $180 / 110$ to $120 \mathrm{mmHg}$ on 2 occasions, 6 hrs apart. All participants had $>500 \mathrm{mg}$ of proteinuria on a $24 \mathrm{hr}$ urine collection measure. Exclusions were women who needed delivery for either a maternal or fetal condition in the 1st 24 hrs.

Interventions

The group assigned to aggressive management were given steroids, and then allowed $48 \mathrm{hrs}$ to lapse before either an induction of labour was attempted or CS carried out. Women assigned to expectant management also had steroids, but were then managed conservatively with bedrest, observations, and nifedipine to control their BP. The indications for delivery in expectant management were: imminent eclampsia, deteriorating renal function, spontaneous preterm labour, absent EDF, or a non-reassuring CTG, and reaching 34 weeks.

Outcomes $\begin{aligned} & \text { Women: days of hospitalisation, imminent eclampsia, eclampsia, HELLP, CS, imminent eclampsia } \\ & \text { deteriorating renal function }\end{aligned}$
$\begin{aligned} & \text { Baby: days gained in utero, gestation at delivery, birthweight, admission to SCBU, SGA, stillbirth, } \\ & \text { neonatal death, 5-minute Apgar score }\end{aligned}$

Notes

In table 2, the total number in the expectant arm was recorded as 10 participants, however, the detail of the table and percentages use the denominator 15 . The total looked as if it was a typographical error. We are seeking information from the author.

Dates of the study: January 2001 and May 2002 
Mesbah 2003 (Continued)

Funding sources: none disclosed

Declarations of interest: none disclosed

\section{Risk of bias}

\begin{tabular}{|c|c|c|}
\hline Bias & Authors' judgement & Support for judgement \\
\hline $\begin{array}{l}\text { Random sequence genera- } \\
\text { tion (selection bias) }\end{array}$ & Low risk & $\begin{array}{l}\text { "Random sequence generated by going through random number tables till we } \\
\text { obtained } 30 \text { pairs of numbers from } 01 \text { to } 30 . "\end{array}$ \\
\hline $\begin{array}{l}\text { Allocation concealment } \\
\text { (selection bias) }\end{array}$ & Low risk & $\begin{array}{l}\text { "Randomly assigned to one of two management groups by withdrawing the } \\
\text { next envelope in a series of } 30 \text { consecutively numbered, sealed, opaque en- } \\
\text { velopes." }\end{array}$ \\
\hline $\begin{array}{l}\text { Blinding of participants } \\
\text { and personnel (perfor- } \\
\text { mance bias) } \\
\text { All outcomes }\end{array}$ & Unclear risk & No blinding reported \\
\hline $\begin{array}{l}\text { Blinding of outcome as- } \\
\text { sessment (detection bias) } \\
\text { All outcomes }\end{array}$ & Unclear risk & No blinding reported \\
\hline $\begin{array}{l}\text { Incomplete outcome data } \\
\text { (attrition bias) } \\
\text { All outcomes }\end{array}$ & High risk & $\begin{array}{l}41 \text { women were recruited, but } 11(27 \%) \text { judged too compromised for expectant } \\
\text { management, and were delivered by CS } \\
5 \text { patients from the expectant group appeared to be missing from results table } \\
2 \text { - no explanation }\end{array}$ \\
\hline $\begin{array}{l}\text { Selective reporting (re- } \\
\text { porting bias) }\end{array}$ & Low risk & All expected outcomes appear to be reported \\
\hline Other bias & High risk & $\begin{array}{l}\text { Severe group were excluded from the study, and no baseline characteristics } \\
\text { described for this group of patients. } 5 \text { patients missing from results for expec- } \\
\text { tant group and no explanation given in the text }\end{array}$ \\
\hline
\end{tabular}

Odendaal 1990

Methods Described as 'randomised'. No further information. Blinding in the assessment of outcome not men-
tioned. Analysis - ITT basis. Follow-up - 100\%

Participants
proteinuria, and symptoms. Women were either already admitted for bedrest and later met criteria, or
admitted because of severe PE, and after 48 hrs stabilisation met entry criteria. 10 primigravidae per
group
Exclusions: oral antihypertensives before trial entry. Fetal or maternal complications necessitating de-
livery within 48 hrs (20 women excluded before randomisation for this reason)
dihydralazine boluses. If steroids not already given, betamethasone $12 \mathrm{mg} \mathrm{IM}$, and again after $24 \mathrm{hrs}$

Interventionist: delivery by either CS or by induction of labour, depending on obstetric circumstances. If cervix not favourable, prostaglandin E2 tablets. If still not favourable after $24 \mathrm{hrs}$, CS Expectant: bedrest on high-risk obstetric ward, BP controlled with prazosin, weekly betamethasone. Maternal and fetal condition monitored intensively. Delivery at 34 weeks, unless indicated earlier 
Odendaal 1990 (Continued)

Outcomes
Women: CS, abruption

Baby: stillbirth, neonatal death, HMD, NEC, pneumothorax, ventilation, days in NICU (mean), birthweight (mean), gestation at delivery (mean)

Notes $\quad 8$ women in the interventionist group and 5 in the expectant group deteriorated while in hospital on bedrest and were randomised immediately.

Dates of the study: the trial recruited from January 1986 to January 1988

Funding sources: South African Medical Research Council

Declarations of interest: none stated

\section{Risk of bias}

\section{Bias Authors' judgement Support for judgement}

Random sequence genera- Unclear risk Not described

tion (selection bias)

\begin{tabular}{lll}
\hline $\begin{array}{l}\text { Allocation concealment } \\
\text { (selection bias) }\end{array}$ & Unclear risk & Not described
\end{tabular}

Blinding of participants $\quad$ Unclear risk
and personnel (perfor-

\begin{tabular}{|c|c|c|}
\hline $\begin{array}{l}\text { Blinding of outcome as- } \\
\text { sessment (detection bias) } \\
\text { All outcomes }\end{array}$ & Unclear risk & Not reported \\
\hline $\begin{array}{l}\text { Incomplete outcome data } \\
\text { (attrition bias) } \\
\text { All outcomes }\end{array}$ & Unclear risk & $\begin{array}{l}58 \text { women eligible with severe PE; } 20 \text { had to be delivered before randomisa- } \\
\text { tion because of severe maternal complications or fetal distress } \\
20 \text { were randomised to the aggressive-management group; } 18 \text { were ran- } \\
\text { domised to the expectant group - not clear from results tables how many } \\
\text { analysed - but presume no loss to follow-up as not described in the text } \\
\text { ITT not stated }\end{array}$ \\
\hline $\begin{array}{l}\text { Selective reporting (re- } \\
\text { porting bias) }\end{array}$ & Low risk & All expected outcomes reported \\
\hline Other bias & Low risk & $\begin{array}{l}\text { Groups seemed similar - including } 20 \text { women excluded prior to randomisation } \\
\text { (correspondence with author) }\end{array}$ \\
\hline
\end{tabular}

\section{Sibai 1994}

\begin{tabular}{ll}
\hline Methods & $\begin{array}{l}\text { Randomisation was by computer-generated random number. Concealment of allocation by consecu- } \\
\text { tively-numbered sealed, opaque, envelopes. Analysis - ITT basis. Follow-up - } 100 \%\end{array}$ \\
\hline Participants & 95 women with severe PE at 28 to 32 weeks' gestation. Severe PE defined as a persistent elevation of BP \\
$\geq 160 / 110 \mathrm{mmHg}$, proteinuria $>500 \mathrm{mg}$ in $24 \mathrm{hrs}$, and uric acid $>5 \mathrm{mg} / \mathrm{dL}$. \\
\\
$\begin{array}{l}\text { Exclusions: associated medical conditions, renal failure, diabetes or connective tissue disorders, asso- } \\
\text { ciated obstetric complications, multiple pregnancies, preterm labour, fetal compromise (estimated fe- } \\
\text { tal weight }<5 \text { th percentile), platelet count }<100,000 / \mathrm{mm}^{3}\end{array}$
\end{tabular}


Sibai 1994 (Continued)

Interventions

All eligible women in $24 \mathrm{hrs}$ before trial entry: betamethasone $12 \mathrm{mg}$, repeated after $24 \mathrm{hrs}, \mathrm{MgSO} 4$ for $24 \mathrm{hrs}$. If BP $160 / 110 \mathrm{mmHg}$ or more, hydralazine or nifedipine, depending on clinician preference

Interventionist: delivery by either CS or by induction of labour, on the basis of their obstetric condition Expectant: maternal and fetal monitoring on an antenatal ward. If either the maternal or fetal condition deteriorated, or they reached 34 weeks' gestation, delivery using the most appropriate method

\begin{tabular}{ll}
\hline Outcomes & Women: eclampsia, gestation at delivery (mean), CS, placental abruption, HELLP syndrome, renal fail- \\
ure, pulmonary oedema, postpartum length of stay \\
Baby: birthweight (mean), admission to NICU, length of stay in NICU, SGA, RDS, NEC, bronchopul- \\
monary dysplasia, cerebral haemorrhage
\end{tabular}

Dotes of the study: the trial recruited from January 1991 to July 1993
Funding sources: not stated
Declarations of interest: none declared

\section{Risk of bias}

\begin{tabular}{lll}
\hline Bias & Authors' judgement & Support for judgement \\
\hline $\begin{array}{l}\text { Random sequence genera- } \\
\text { tion (selection bias) }\end{array}$ & Low risk & "Computer-generated random assignments" \\
\hline $\begin{array}{l}\text { Allocation concealment } \\
\text { (selection bias) }\end{array}$ & Low risk & "Consecutively numbered, sealed, opaque envelopes" \\
\hline $\begin{array}{l}\text { Blinding of participants } \\
\text { and personnel (perfor- } \\
\text { mance bias) }\end{array}$ & Unclear risk & Not reported \\
All outcomes & \\
\hline
\end{tabular}

\begin{tabular}{lll}
\hline $\begin{array}{l}\text { Blinding of outcome as- } \\
\text { sessment (detection bias) } \\
\text { All outcomes }\end{array}$ & Unclear risk & Not reported \\
\hline $\begin{array}{l}\text { Incomplete outcome data } \\
\text { (attrition bias) }\end{array}$ & Low risk & $\begin{array}{l}129 \text { women had severe PE, but } 32 \text { of these were ineligible because they met } 1 \\
\text { or more of the exclusion criteria, and } 2 \text { refused to participate }-95 \text { women were } \\
\text { randomised (expectant management } \mathrm{N}=49 \text {; aggressive management } \mathrm{N}=46)\end{array}$ \\
& $\begin{array}{l}\text { All women appeared to have been accounted for in the results. Appeared to be } \\
\text { ITT }\end{array}$
\end{tabular}

\begin{tabular}{lll}
\hline $\begin{array}{l}\text { Selective reporting (re- } \\
\text { porting bias) }\end{array}$ & Low risk & All expected outcomes appeared to have been reported upon \\
\hline Other bias & Low risk & The 2 groups were similar with respect to clinical and laboratory findings. \\
\hline
\end{tabular}

Thornton 2004 (GRIT)

\begin{tabular}{l} 
Multi-centre randomised controlled trial \\
Setting: 69 hospitals in 13 European countries \\
\hline
\end{tabular}


Thornton 2004 (GRIT) (Continued)

Inclusion criteria: pregnant women with fetal compromise between 24 and 36 weeks, an umbilical artery Doppler waveform recorded, and clinical uncertainty whether immediate delivery was indicated

Interventions Immediate delivery ( $=273$; IPD N = 141): deliver now, within 48 hrs to permit completion of a steroid course

Delayed delivery ( $N=274$; IPD N = 121): defer delivery, meaning until delivery could safely be delayed no longer

Infant survival to hospital discharge and the Griffith's development quotient at 2 years
The trial was for compromised preterm fetus: a subset of women within this trial had s
were available for this subset and these were the data which were extracted and analysed
view. The outcomes for this subset were as follows.
For the woman: CS
For the baby:
- intraventricular haemorrhage, hypoxic ischaemic encephalopathy, or both
- Apgar score at 5 minutes
- neonatal seizures
- NEC
- ventilation
- measures of long-term growth and development (e.g. CP diagnosis, Griffiths score)
- gestational age at birth

Notes

Only a subset of IPD data were included and analysed in this review (women with hypertension plus either proteinuria or IUGR).

Dates of the study: November 1993 to March 2001

Funding sources: UK Medical Research Council, European Union Concerted Action, and the Dutch Princess Beatrix Foundation

Declarations of interest: none mentioned

\section{Risk of bias}

\begin{tabular}{lll}
\hline Bias & Authors' judgement & Support for judgement \\
\hline $\begin{array}{l}\text { Random sequence genera- } \\
\text { tion (selection bias) }\end{array}$ & Low risk & $\begin{array}{l}\text { "A paper-based number sequence with balanced blocks of } 8 \text { to } 12 \text { weeks used } \\
\text { except during office hours, when a computer-generated sequence was used" }\end{array}$ \\
\hline $\begin{array}{l}\text { Allocation concealment } \\
\text { (selection bias) }\end{array}$ & Low risk & $\begin{array}{l}\text { "An independent programmer organised allocation, using both randomisation } \\
\text { and minimisation." "The process was designed to mask allocation from partic- } \\
\text { ipating clinicians, including those with access to the central trial office." }\end{array}$ \\
\hline $\begin{array}{l}\text { Blinding of participants } \\
\text { and personnel (perfor- } \\
\text { mance bias) }\end{array}$ & Low risk & $\begin{array}{l}\text { Not possible to blind - but most of the outcomes not likely to be influenced by } \\
\text { lack of blinding. }\end{array}$ \\
\hline $\begin{array}{l}\text { Blinding of outcome as- } \\
\text { sessment (detection bias) } \\
\text { All outcomes }\end{array}$ & Low risk & $\begin{array}{l}\text { Some blinding of outcome assessment for long-term outcomes, such as Grif- } \\
\text { fiths assessment: "Assessors were masked to the child's group allocations." }\end{array}$ \\
\hline $\begin{array}{l}\text { Incomplete outcome data } \\
\text { (attrition bias) } \\
\text { All outcomes }\end{array}$ & Unclear risk & $\begin{array}{l}\text { A subset of IPD data was provided of women with severe PE (N=262 - hyper- } \\
\text { tension, IUGR, proteinuria, or a combination). It was not possible to tell how }\end{array}$
\end{tabular}


Thornton 2004 (GRIT) (Continued)

complete this dataset was, as it was provided by the authors of the original study.

\begin{tabular}{lll}
\hline $\begin{array}{l}\text { Selective reporting (re- } \\
\text { porting bias) }\end{array}$ & Low risk & All expected outcomes appeared to have been reported upon. \\
\hline Other bias & Unclear risk & $\begin{array}{l}\text { Unclear. Other bias may have been introduced, as only a subset of the original } \\
\text { randomised sample provided data for analysis. }\end{array}$ \\
\hline
\end{tabular}

Vigil-De Gracia 2013

\begin{tabular}{ll}
\hline Methods & $\begin{array}{l}\text { Randomised controlled trial (open label). } 8 \text { tertiary teaching hospitals in Latin America with experience } \\
\text { of managing severe PE. } 425 \text { eligible women, } 158 \text { declined to participate, } 267 \text { randomised }\end{array}$ \\
\hline Participants & $\begin{array}{l}\text { Inclusion criteria: pregnant women between } 28 \text { and } 33 \text { weeks' gestation with severe PE, severe gesta- } \\
\text { tional hypertension, and super-imposed PE } \\
\text { Exclusion criteria: pregnant women with HELLP syndrome, renal failure, vaginal bleeding, spontaneous } \\
\text { rupture of membranes, placenta praevia, gestational diabetes or diabetes mellitus, autoimmune dis- } \\
\text { ease, fetal growth restriction, reduced amniotic fluid, and reversed EDF }\end{array}$
\end{tabular}

Interventions

Experimental intervention: delivery between 24 and $72 \mathrm{hrs}$ following the administration of glucocorticoids for fetal lung maturity. Total number randomised: $\mathrm{N}=133$

Control or comparison intervention: glucocorticoid administration, then planned expectant management with delivery for maternal or fetal indications, or reaching 34 weeks. Total number randomised: $\mathrm{N}$ $=134$ (131 analysed)

Primary outcome: perinatal mortality (fetal and neonatal death)
Secondary outcomes: composite neonatal morbidities (RDS, IVH, necrotizing enterocolitis, neonatal
sepsis); neonatal data (birthweight, SGA, Apgar scores at 1 and 5 minutes, NICU admission, length of
NICU admission stay, sex (female) of baby); caesarean delivery, pregnancy prolongation, maternal mor-
bidities (placental abruption, pulmonary edema, the HELLP syndrome, renal insufficiency, eclampsia,
disseminated intravascular coagulation, oliguria), and death

Notes Dates of the study: August 2010 to August 2012

Funding sources: Marjorie Milham Research Fund, Pennsylvania Hospital, Perelman School of Medicine, University of Pennsylvannia

Declarations of interest: "The authors report no conflict of interest."

\section{Risk of bias}

\begin{tabular}{lll}
\hline Bias & Authors' judgement & Support for judgement \\
\hline $\begin{array}{l}\text { Random sequence genera- } \\
\text { tion (selection bias) }\end{array}$ & Low risk & $\begin{array}{l}\text { Randomly allocated, using computer-generated code with variable block size } \\
\text { of } 4 \text { and } 6\end{array}$ \\
\hline $\begin{array}{l}\text { Allocation concealment } \\
\text { (selection bias) }\end{array}$ & Unclear risk & $\begin{array}{l}\text { Central allocation for each hospital made by the principal investigator. Sealed } \\
\text { envelopes were used, though does not specify whether they were sequentially } \\
\text { numbered and opaque }\end{array}$ \\
\hline
\end{tabular}

Blinding of participants High risk Open-label trial due to the nature of the intervention
and personnel (perfor-
mance bias)


Vigil-De Gracia 2013 (Continued)

All outcomes

\begin{tabular}{|c|c|c|}
\hline $\begin{array}{l}\text { Blinding of outcome as- } \\
\text { sessment (detection bias) } \\
\text { All outcomes }\end{array}$ & Unclear risk & $\begin{array}{l}\text { An attempt was made to blind the treatment allocation to the data abstracter } \\
\text { - especially the neonatologist. However, most outcomes depended on clinical } \\
\text { diagnoses and others on the responses to those diagnoses. }\end{array}$ \\
\hline
\end{tabular}

\begin{tabular}{ll}
\hline $\begin{array}{l}\text { Incomplete outcome data } \\
\text { (attrition bias) }\end{array}$ & $\begin{array}{l}\text { The authors stated that } 2 \text { patients did not complete the study because they } \\
\text { refused to remain in the hospital, and } 1 \text { did not receive the correct treatment } \\
\text { due to physician error. These } 3 \text { patients were excluded from the analysis. They } \\
\text { said the data were not available for these } 3 \text { women. All } 3 \text { women were in the } \\
\text { expectant management group. The authors reported that the analysis was on } \\
\text { an ITT basis. }\end{array}$
\end{tabular}

\begin{tabular}{lll}
\hline $\begin{array}{l}\text { Selective reporting (re- } \\
\text { porting bias) }\end{array}$ & Unclear risk & $\begin{array}{l}\text { The trial was registered. However, the planned secondary outcomes were list- } \\
\text { ed only as "perinatal complications and maternal complications". }\end{array}$ \\
\hline Other bias & Unclear risk & $\begin{array}{l}\text { Baseline characteristics - no differences between groups. Minimal loss to fol- } \\
\text { low-up. Two women refused to remain in hospital and one women received in- } \\
\text { correct treatment due to physician error. }\end{array}$ \\
\hline
\end{tabular}

BP: blood pressure

CP: cerebral palsy

CS: caesarean section

CTG: cardiotocography

EDF: end diastolic flow

HELLP: haemolysis, elevated liver enzymes, and lowered platelets

HMD: hyaline membrane disease

hrs: hours

IM: intramuscular

IPD: individual patient data

ITT: intention-to-treat

IUGR: intrauterine growth restriction

MgSO4: magnesium sulphate

NEC: necrotising enterocolitis

NICU: neonatal intensive care unit

PE: pre-eclampsia

RDS: respiratory distress syndrome

SCBU: special care baby unit

SGA: small-for-gestational age

Characteristics of excluded studies [ordered by study ID]

\begin{tabular}{ll}
\hline Study & Reason for exclusion \\
\hline Gruppo di Studio1998 & Not women with severe pre-eclampsia \\
& $\begin{array}{l}\text { This randomised trial compared routine treatment with calcium channel blockers in mild to mod- } \\
\text { erate hypertension. }\end{array}$ \\
\hline Langenveld 2011 & Not women with severe pre-eclampsia \\
& $\begin{array}{l}\text { This multi-centre, randomised trial compared induction of labour versus expectant monitoring for } \\
\text { gestation hypertension or mild pre-eclampsia. }\end{array}$
\end{tabular}


DATA AND ANALYSES

Comparison 1. Interventionist care versus expectant (delayed delivery) care for severe pre-eclampsia

\begin{tabular}{|c|c|c|c|c|}
\hline Outcome or subgroup title & No. of studies & $\begin{array}{l}\text { No. of partici- } \\
\text { pants }\end{array}$ & Statistical method & Effect size \\
\hline 1 Maternal death & 2 & 320 & Risk Ratio (M-H, Fixed, 95\% Cl) & $0.0[0.0,0.0]$ \\
\hline 2 Eclampsia & 2 & 359 & Risk Ratio (M-H, Fixed, 95\% Cl) & $0.98[0.06,15.58]$ \\
\hline 3 Pulmonary oedema & 3 & 415 & Risk Ratio (M-H, Fixed, 95\% Cl) & $0.45[0.07,3.00]$ \\
\hline 4 HELLP syndrome & 2 & 359 & Risk Ratio (M-H, Fixed, 95\% Cl) & $1.09[0.62,1.91]$ \\
\hline $\begin{array}{l}5 \text { Death of the baby (all stillbirths, } \\
\text { neonatal, and infant deaths) }\end{array}$ & 6 & 760 & Risk Ratio (M-H, Fixed, 95\% Cl) & $1.08[0.74,1.60]$ \\
\hline $\begin{array}{l}6 \text { Death of the baby (subgrouped } \\
\text { by time of death) }\end{array}$ & 6 & & Risk Ratio (M-H, Fixed, 95\% Cl) & Subtotals only \\
\hline 6.1 Stillbirth & 5 & 700 & Risk Ratio (M-H, Fixed, 95\% Cl) & $0.30[0.07,1.23]$ \\
\hline 6.2 Perinatal death & 3 & 343 & Risk Ratio (M-H, Fixed, 95\% Cl) & $1.11[0.62,1.99]$ \\
\hline 6.3 Neonatal death & 5 & 485 & Risk Ratio (M-H, Fixed, 95\% Cl) & $1.32[0.80,2.19]$ \\
\hline 6.4 Death after 28 days & 1 & 38 & Risk Ratio (M-H, Fixed, 95\% Cl) & $1.8[0.18,18.21]$ \\
\hline $\begin{array}{l}7 \text { Intraventricular haemorrhage or } \\
\text { hypoxic ischaemic encephalopa- } \\
\text { thy }\end{array}$ & 2 & 537 & Risk Ratio (M-H, Fixed, 95\% Cl) & $1.94[1.15,3.29]$ \\
\hline 8 Caesarean section & 6 & 745 & $\begin{array}{l}\text { Risk Ratio (M-H, Random, 95\% } \\
\mathrm{CI})\end{array}$ & $1.01[0.91,1.12]$ \\
\hline 9 Renal failure & 3 & 397 & Risk Ratio (M-H, Fixed, 95\% Cl) & $0.32[0.05,1.99]$ \\
\hline 10 Placental abruption & 4 & 453 & Risk Ratio (M-H, Fixed, 95\% Cl) & $0.42[0.18,0.96]$ \\
\hline 11 Hyaline membrane disease & 2 & 133 & Risk Ratio (M-H, Fixed, 95\% Cl) & $2.30[1.39,3.81]$ \\
\hline 12 Baby ventilated & 2 & 300 & Risk Ratio (M-H, Fixed, 95\% Cl) & $1.50[1.11,2.02]$ \\
\hline 13 Gestation at birth (days) & 4 & 425 & $\begin{array}{l}\text { Mean Difference (IV, Random, } \\
95 \% \mathrm{CI})\end{array}$ & $-9.91[-16.37,-3.45]$ \\
\hline 14 Necrotising enterocolitis & 4 & 670 & Risk Ratio (M-H, Fixed, 95\% Cl) & $1.79[0.84,3.81]$ \\
\hline 15 Small-for-gestational age & 3 & 400 & Risk Ratio (M-H, Fixed, 95\% Cl) & $0.38[0.24,0.61]$ \\
\hline $\begin{array}{l}16 \text { Low Apgar score at five minutes } \\
\text { ( }<7 \text { at five minutes) }\end{array}$ & 1 & 262 & Risk Ratio (M-H, Fixed, 95\% Cl) & $1.48[0.87,2.50]$ \\
\hline 17 Neonatal seizures & 1 & 262 & Risk Ratio (M-H, Fixed, 95\% Cl) & $2.57[0.27,24.43]$ \\
\hline
\end{tabular}




\begin{tabular}{lllll}
\hline Outcome or subgroup title & No. of studies & $\begin{array}{l}\text { No. of partici- } \\
\text { pants }\end{array}$ & Statistical method & Effect size \\
\hline $\begin{array}{l}18 \text { Measures of long-term growth \& } \\
\text { development (cerebral palsy) }\end{array}$ & 1 & 262 & Risk Ratio (M-H, Fixed, 95\% Cl) & $6.01[0.75,48.14]$ \\
\hline $\begin{array}{l}19 \text { Measures of long-term growth \& } \\
\text { development (poor hearing, use of } \\
\text { hearing aid) }\end{array}$ & 1 & 262 & Risk Ratio (M-H, Fixed, 95\% Cl) & $0.34[0.07,1.74]$ \\
\hline $\begin{array}{l}20 \text { Measures of long-term growth \& } \\
\text { development (impaired vision) }\end{array}$ & 1 & 262 & Risk Ratio (M-H, Fixed, 95\% Cl) & 4.29 [0.51, 36.22] \\
\hline $\begin{array}{l}21 \text { Admission to neonatal intensive } \\
\text { care unit }\end{array}$ & 3 & 400 & $\begin{array}{l}\text { Risk Ratio (M-H, Random, 95\% } \\
\text { Cl) }\end{array}$ & 1.19 [0.89, 1.60] \\
\hline $\begin{array}{l}22 \text { Length of stay in neonatal in- } \\
\text { tensive care unit (days) }\end{array}$ & 3 & 400 & $\begin{array}{l}\text { Mean Difference (IV, Random, } \\
95 \% \text { Cl) }\end{array}$ & $7.38[-0.45,15.20]$ \\
\hline
\end{tabular}

Analysis 1.1. Comparison 1 Interventionist care versus expectant (delayed delivery) care for severe pre-eclampsia, Outcome 1 Maternal death.

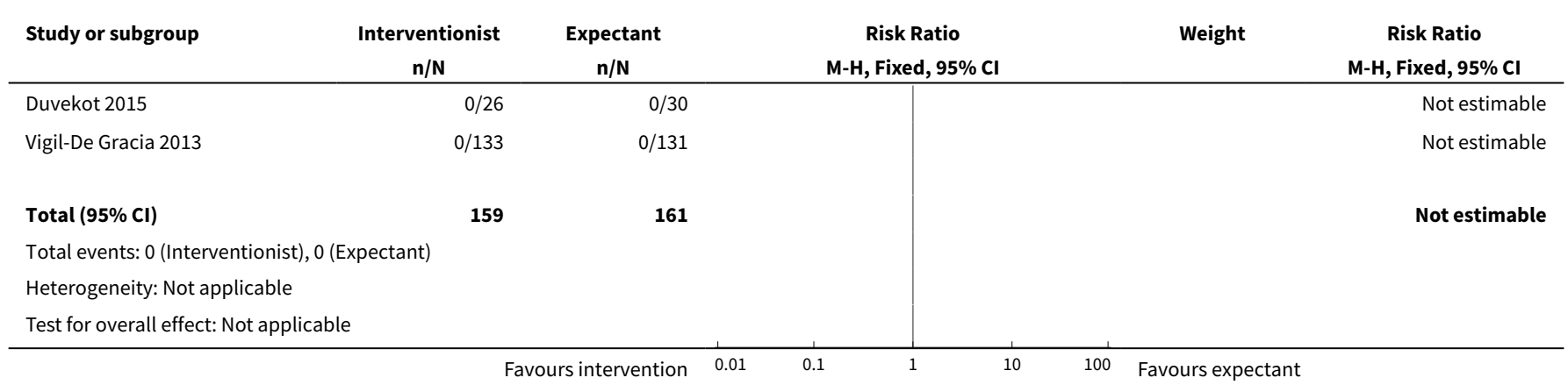

Analysis 1.2. Comparison 1 Interventionist care versus expectant (delayed delivery) care for severe pre-eclampsia, Outcome 2 Eclampsia.

\begin{tabular}{|c|c|c|c|c|c|}
\hline Study or subgroup & $\begin{array}{c}\text { Interventionist } \\
\mathrm{n} / \mathrm{N}\end{array}$ & $\begin{array}{c}\text { Expectant } \\
n / N\end{array}$ & $\begin{array}{c}\text { Risk Ratio } \\
\text { M-H, Fixed, 95\% Cl }\end{array}$ & Weight & $\begin{array}{c}\text { Risk Ratio } \\
\text { M-H, Fixed, } 95 \% \mathrm{Cl}\end{array}$ \\
\hline Sibai 1994 & $0 / 46$ & $0 / 49$ & & & Not estimable \\
\hline Vigil-De Gracia 2013 & $1 / 133$ & $1 / 131$ & & $100 \%$ & $0.98[0.06,15.58]$ \\
\hline Total $(95 \% \mathrm{Cl})$ & 179 & 180 & & $100 \%$ & $0.98[0.06,15.58]$ \\
\hline \multicolumn{6}{|c|}{ Total events: 1 (Interventionist), 1 (Expectant) } \\
\hline Test for overall effect & & & & & \\
\hline
\end{tabular}


Analysis 1.3. Comparison 1 Interventionist care versus expectant (delayed delivery) care for severe pre-eclampsia, Outcome 3 Pulmonary oedema.

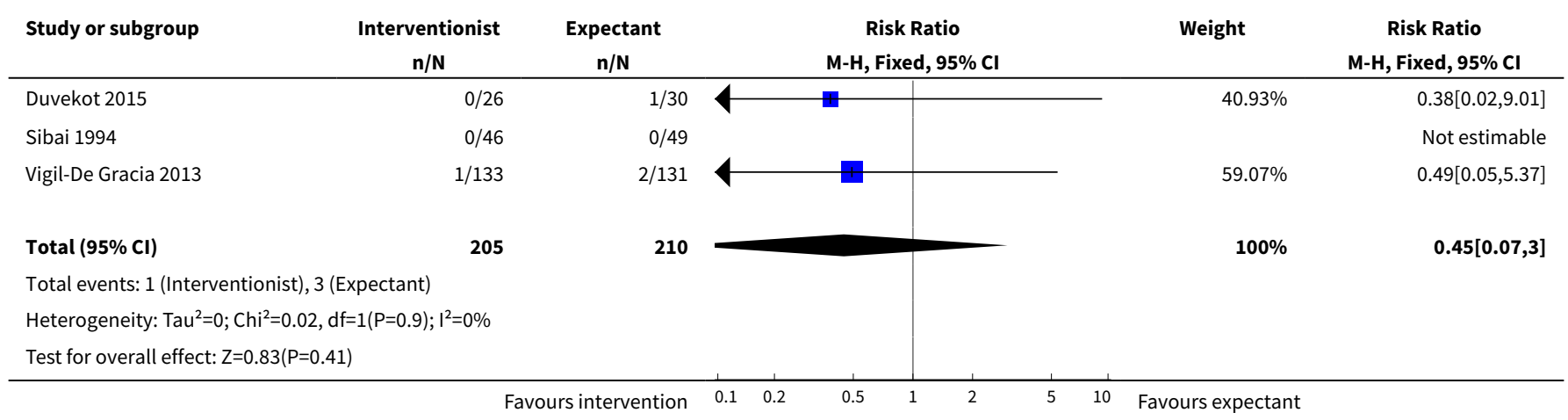

\section{Analysis 1.4. Comparison 1 Interventionist care versus expectant (delayed} delivery) care for severe pre-eclampsia, Outcome 4 HELLP syndrome.

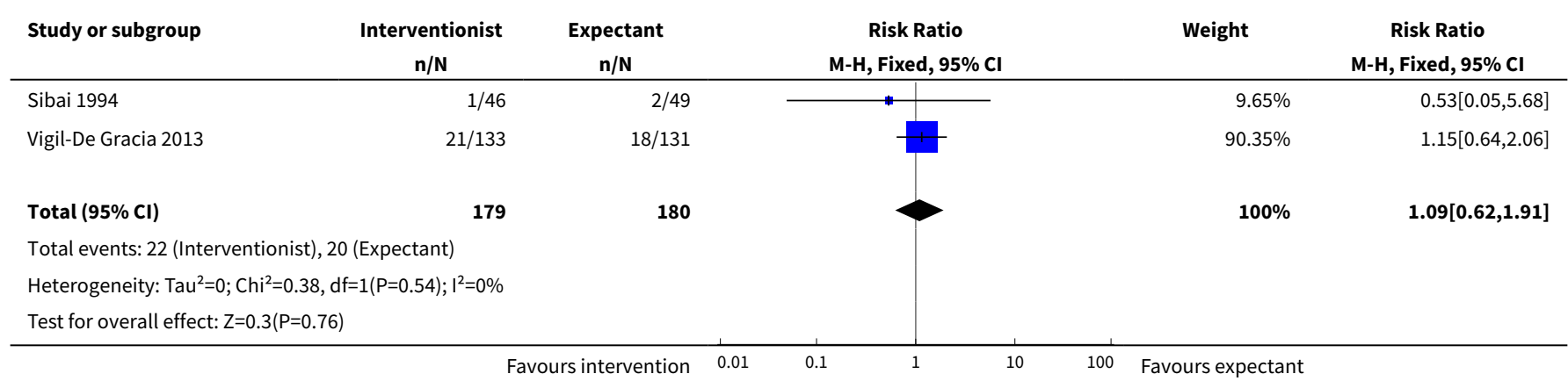

Analysis 1.5. Comparison 1 Interventionist care versus expectant (delayed delivery) care for severe pre-eclampsia, Outcome 5 Death of the baby (all stillbirths, neonatal, and infant deaths).

\begin{tabular}{|c|c|c|c|c|c|}
\hline Study or subgroup & $\begin{array}{c}\text { Interventionist } \\
\mathrm{n} / \mathrm{N} \\
\end{array}$ & $\begin{array}{c}\text { Expectant } \\
\mathrm{n} / \mathrm{N} \\
\end{array}$ & $\begin{array}{c}\text { Risk Ratio } \\
\text { M-H, Fixed, 95\% Cl }\end{array}$ & Weight & $\begin{array}{c}\text { Risk Ratio } \\
\text { M-H, Fixed, 95\% Cl }\end{array}$ \\
\hline Sibai 1994 & $0 / 46$ & $0 / 49$ & & & Not estimable \\
\hline Duvekot 2015 & $1 / 29$ & $1 / 31$ & & $2.32 \%$ & $1.07[0.07,16.31]$ \\
\hline Odendaal 1990 & $5 / 20$ & $3 / 18$ & & $7.59 \%$ & $1.5[0.42,5.41]$ \\
\hline Mesbah 2003 & $6 / 15$ & $4 / 15$ & & $9.61 \%$ & $1.5[0.53,4.26]$ \\
\hline Vigil-De Gracia 2013 & $13 / 137$ & $12 / 138$ & & $28.74 \%$ & $1.09[0.52,2.31]$ \\
\hline Total $(95 \% \mathrm{Cl})$ & 388 & 372 & & $100 \%$ & $1.08[0.74,1.6]$ \\
\hline \multicolumn{6}{|c|}{ Total events: 47 (Interventionist), 40 (Expectant) } \\
\hline \multicolumn{6}{|c|}{ Heterogeneity: $\operatorname{Tau}^{2}=0 ; \mathrm{Chi}^{2}=0.86, \mathrm{df}=4(\mathrm{P}=0.93) ; \mathrm{I}^{2}=0 \%$} \\
\hline Test for overall effect: 2 & & & & & \\
\hline
\end{tabular}


Analysis 1.6. Comparison 1 Interventionist care versus expectant (delayed delivery) care for severe pre-eclampsia, Outcome 6 Death of the baby (subgrouped by time of death).

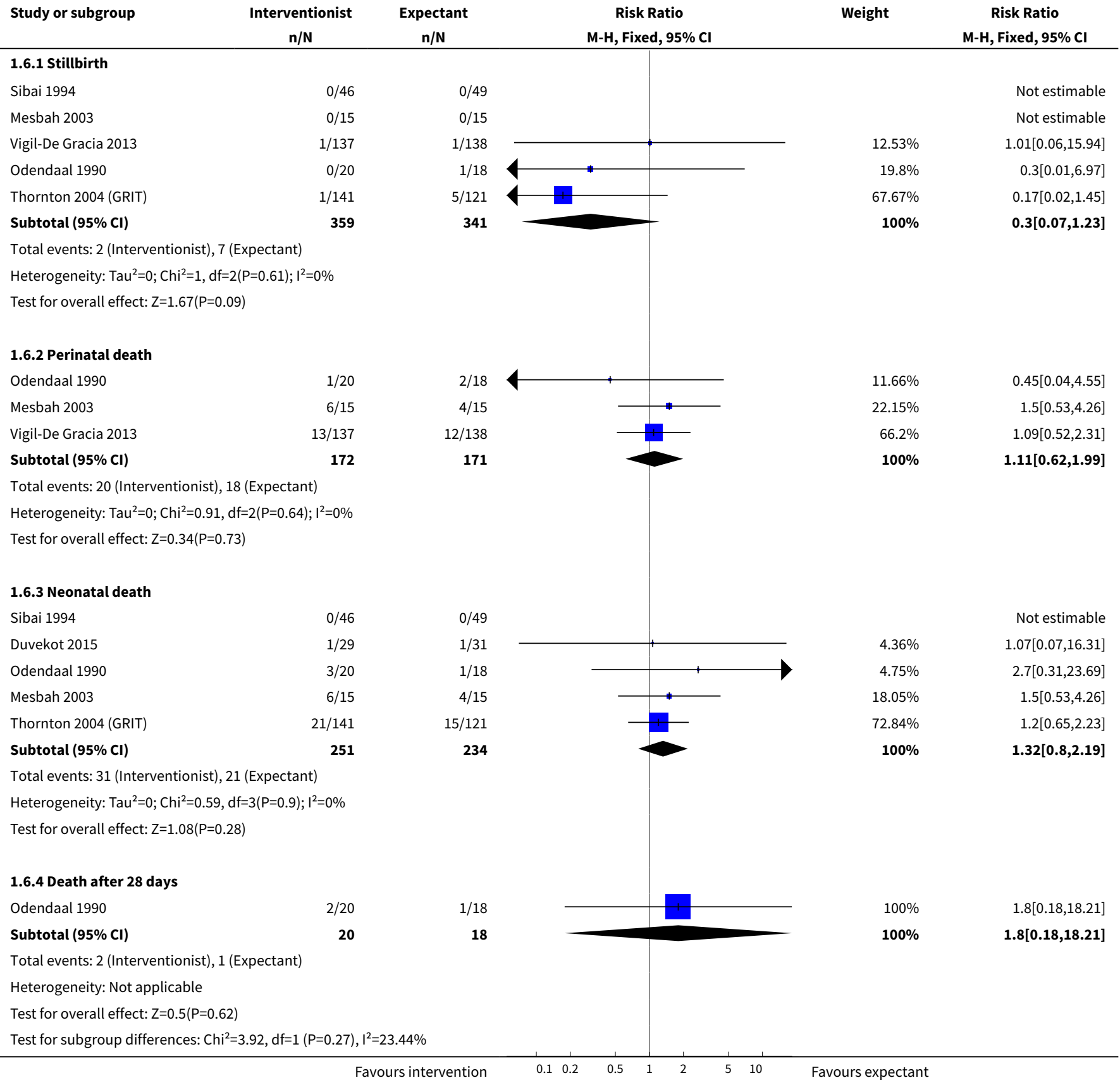

\section{Analysis 1.7. Comparison 1 Interventionist care versus expectant (delayed delivery) care for severe pre-eclampsia, Outcome 7 Intraventricular haemorrhage or hypoxic ischaemic encephalopathy.}

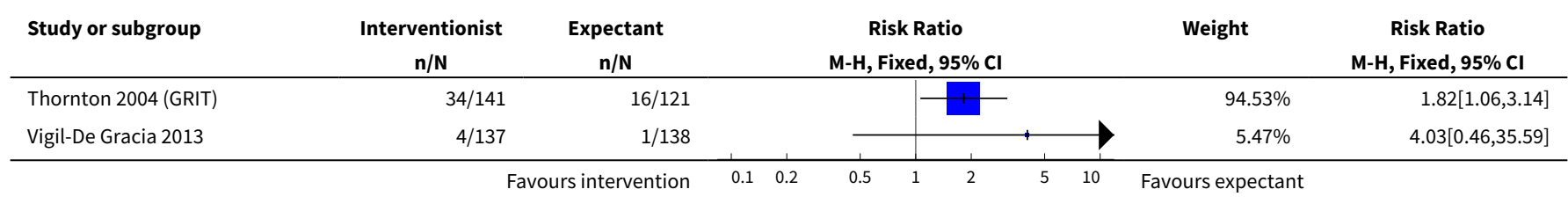




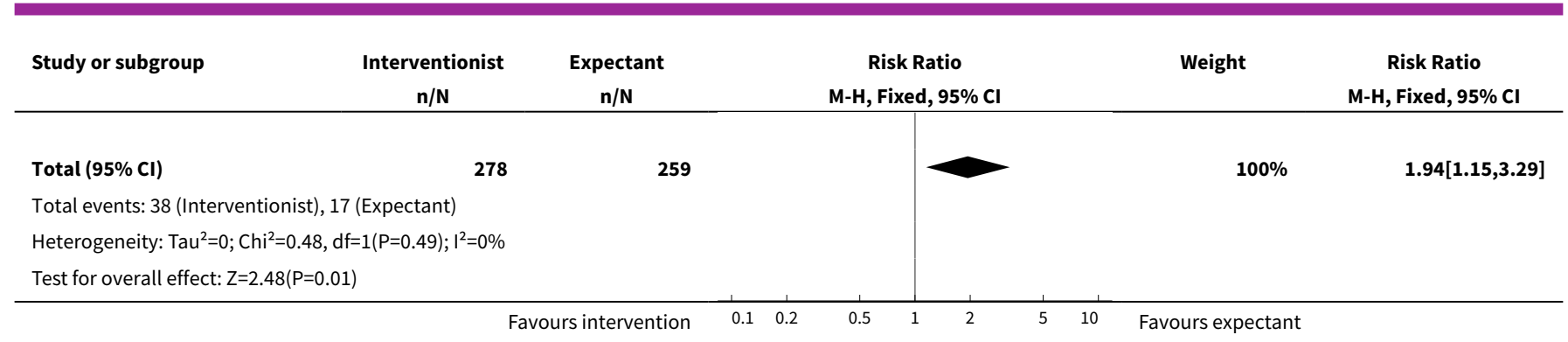

\section{Analysis 1.8. Comparison 1 Interventionist care versus expectant (delayed delivery) care for severe pre-eclampsia, Outcome 8 Caesarean section.}

\begin{tabular}{|c|c|c|c|c|c|}
\hline Study or subgroup & $\begin{array}{c}\text { Interventionist } \\
\mathrm{n} / \mathrm{N} \\
\end{array}$ & $\begin{array}{c}\text { Expectant } \\
\mathrm{n} / \mathrm{N}\end{array}$ & $\begin{array}{c}\text { Risk Ratio } \\
\text { M-H, Random, } 95 \% \text { Cl }\end{array}$ & Weight & $\begin{array}{c}\text { Risk Ratio } \\
\text { M-H, Random, } 95 \% \mathrm{Cl}\end{array}$ \\
\hline Mesbah 2003 & $11 / 15$ & $9 / 15$ & & $3.79 \%$ & $1.22[0.73,2.04]$ \\
\hline Odendaal 1990 & $14 / 20$ & $15 / 18$ & & $7.14 \%$ & $0.84[0.59,1.2]$ \\
\hline Duvekot 2015 & $21 / 26$ & $27 / 30$ & $\longrightarrow$ & $13.78 \%$ & $0.9[0.72,1.12]$ \\
\hline Sibai 1994 & $39 / 46$ & $36 / 49$ & * & $14.89 \%$ & $1.15[0.94,1.42]$ \\
\hline Vigil-De Gracia 2013 & $118 / 133$ & $124 / 131$ & $\rightarrow-$ & $30.04 \%$ & $0.94[0.87,1.01]$ \\
\hline Total $(95 \% \mathrm{Cl})$ & 381 & 364 & & $100 \%$ & $1.01[0.91,1.12]$ \\
\hline \multicolumn{6}{|c|}{ Total events: 340 (Interventionist), 318 (Expectant) } \\
\hline \multicolumn{6}{|c|}{ Heterogeneity: Tau $^{2}=0.01 ; \mathrm{Chi}^{2}=13.69, \mathrm{df}=5(\mathrm{P}=0.02) ; \mathrm{I}^{2}=63.49 \%$} \\
\hline Test for overall effect: 2 & & & & & \\
\hline
\end{tabular}

Analysis 1.9. Comparison 1 Interventionist care versus expectant (delayed delivery) care for severe pre-eclampsia, Outcome 9 Renal failure.

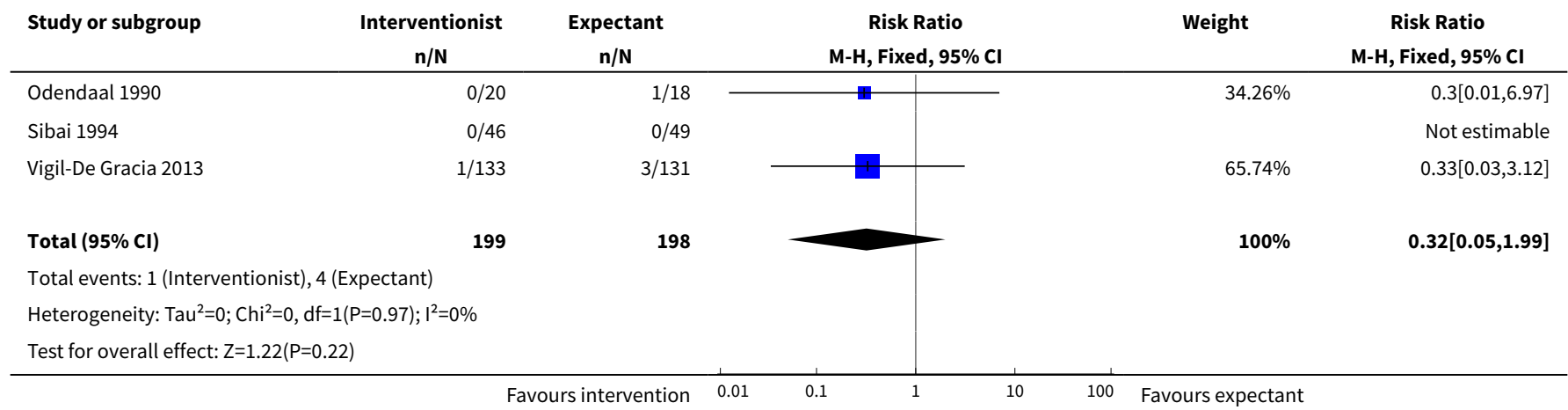


Analysis 1.10. Comparison 1 Interventionist care versus expectant (delayed delivery) care for severe pre-eclampsia, Outcome 10 Placental abruption.

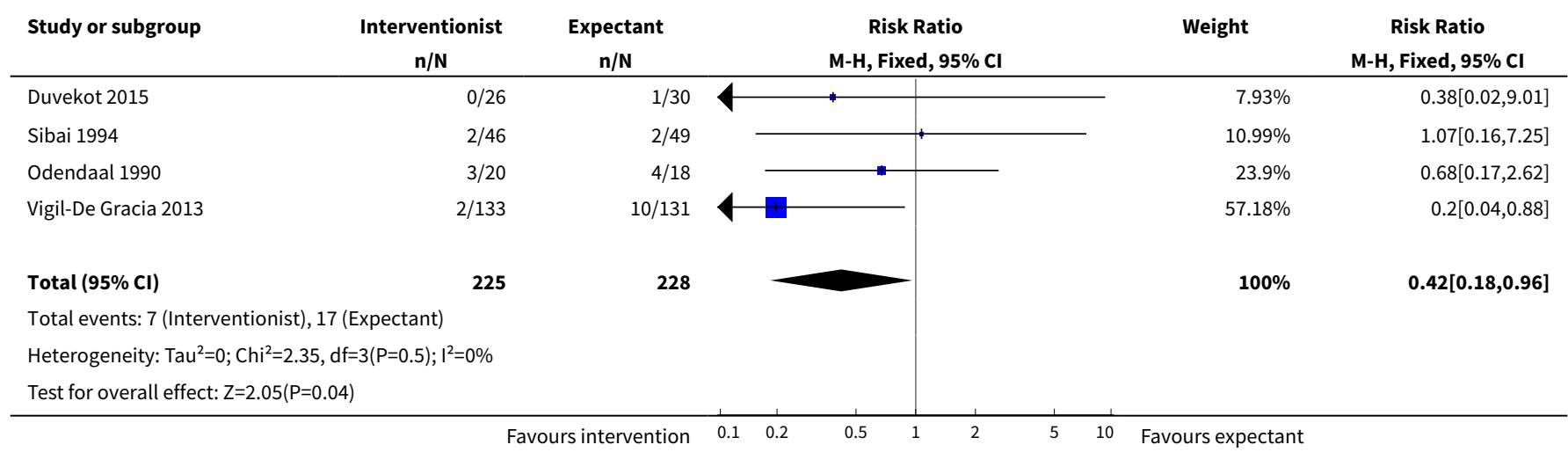

Analysis 1.11. Comparison 1 Interventionist care versus expectant (delayed delivery) care for severe pre-eclampsia, Outcome 11 Hyaline membrane disease.

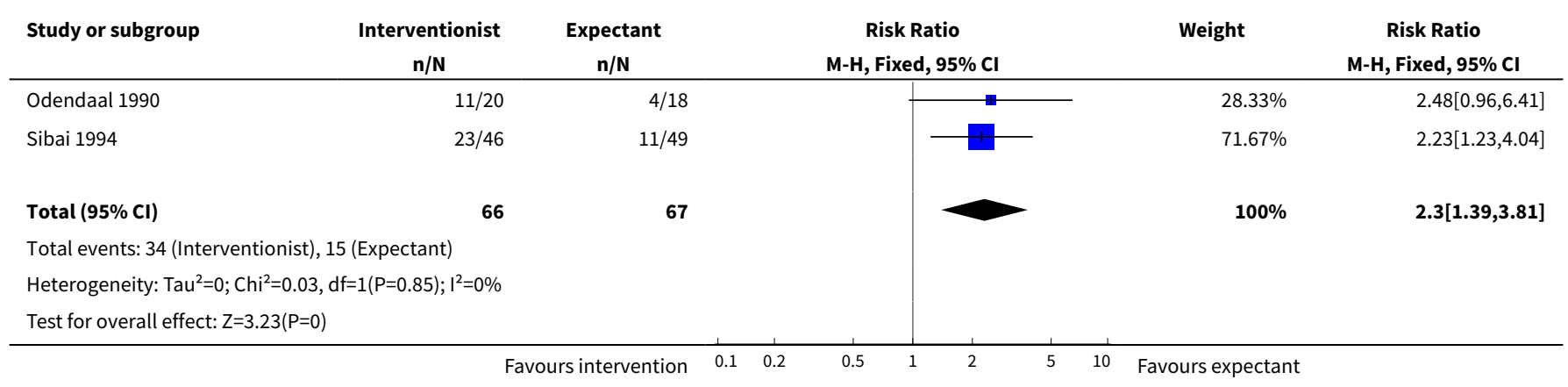

Analysis 1.12. Comparison 1 Interventionist care versus expectant (delayed delivery) care for severe pre-eclampsia, Outcome 12 Baby ventilated.

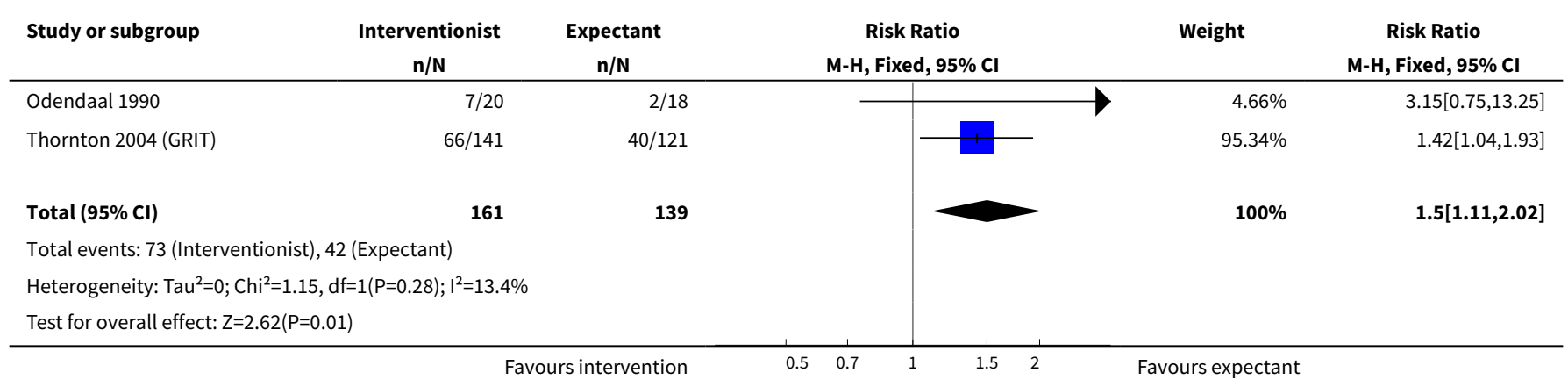


Analysis 1.13. Comparison 1 Interventionist care versus expectant (delayed delivery) care for severe pre-eclampsia, Outcome 13 Gestation at birth (days).

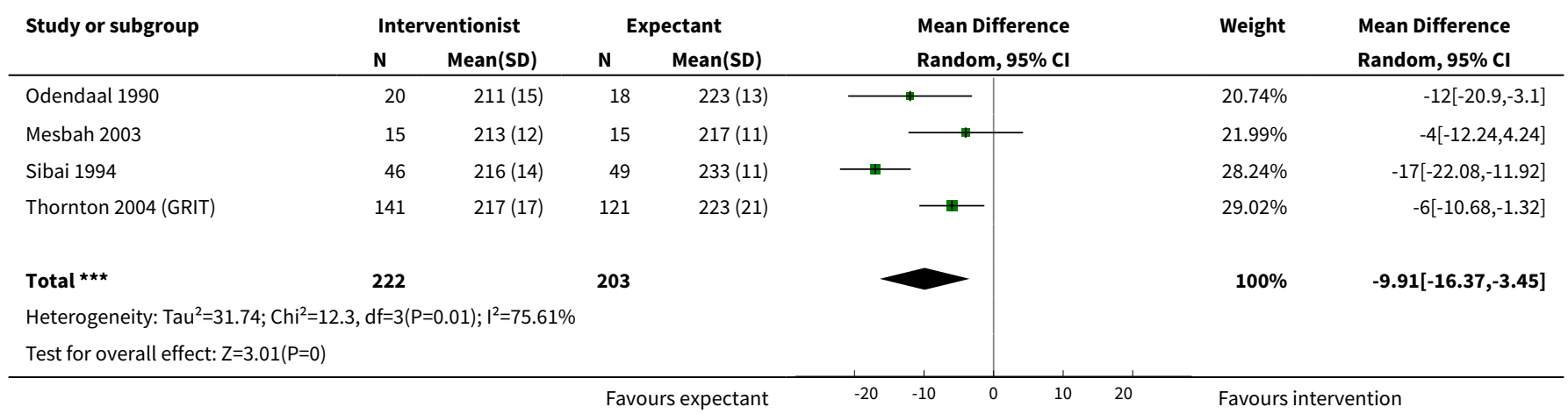

Analysis 1.14. Comparison 1 Interventionist care versus expectant (delayed delivery) care for severe pre-eclampsia, Outcome 14 Necrotising enterocolitis.

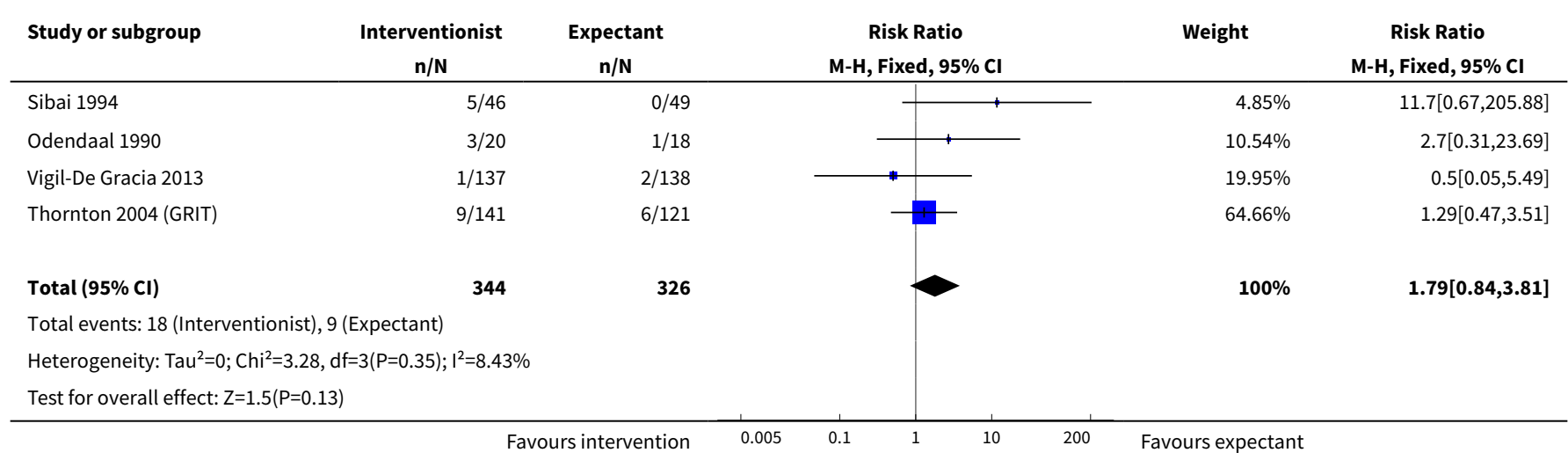

Analysis 1.15. Comparison 1 Interventionist care versus expectant (delayed delivery) care for severe pre-eclampsia, Outcome 15 Small-for-gestational age.

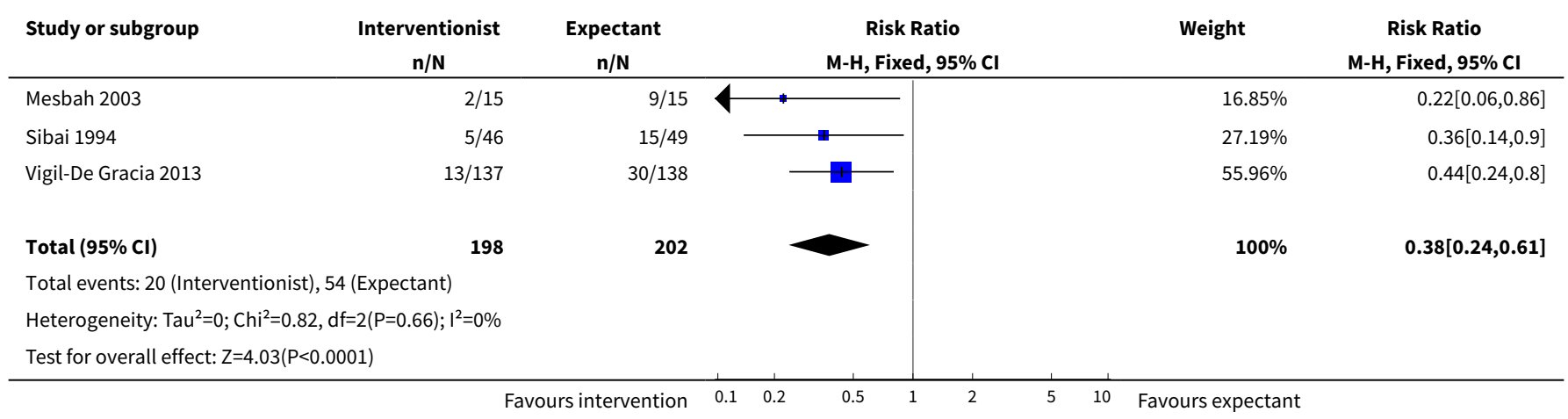


Analysis 1.16. Comparison 1 Interventionist care versus expectant (delayed delivery) care for severe pre-eclampsia, Outcome 16 Low Apgar score at five minutes ( $<7$ at five minutes).

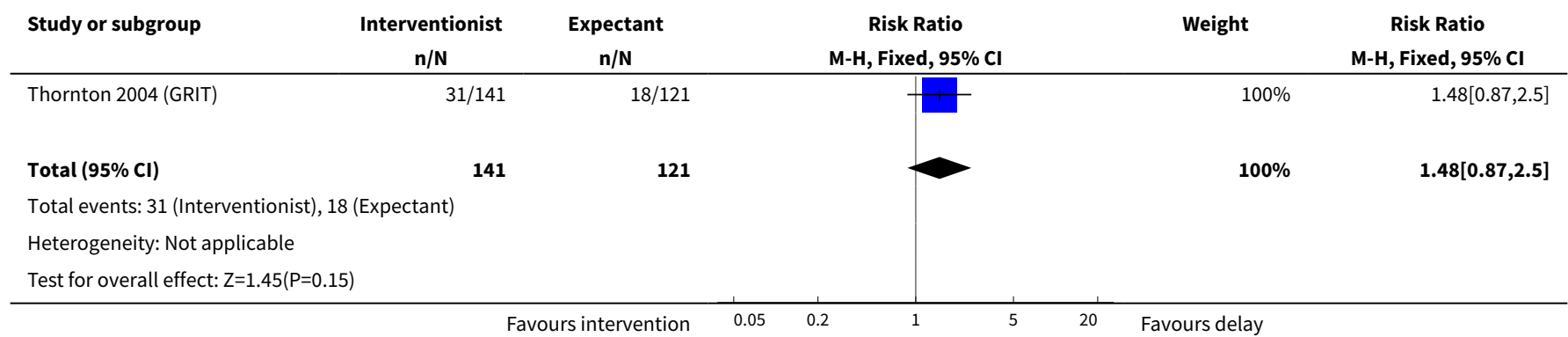

Analysis 1.17. Comparison 1 Interventionist care versus expectant (delayed delivery) care for severe pre-eclampsia, Outcome 17 Neonatal seizures.

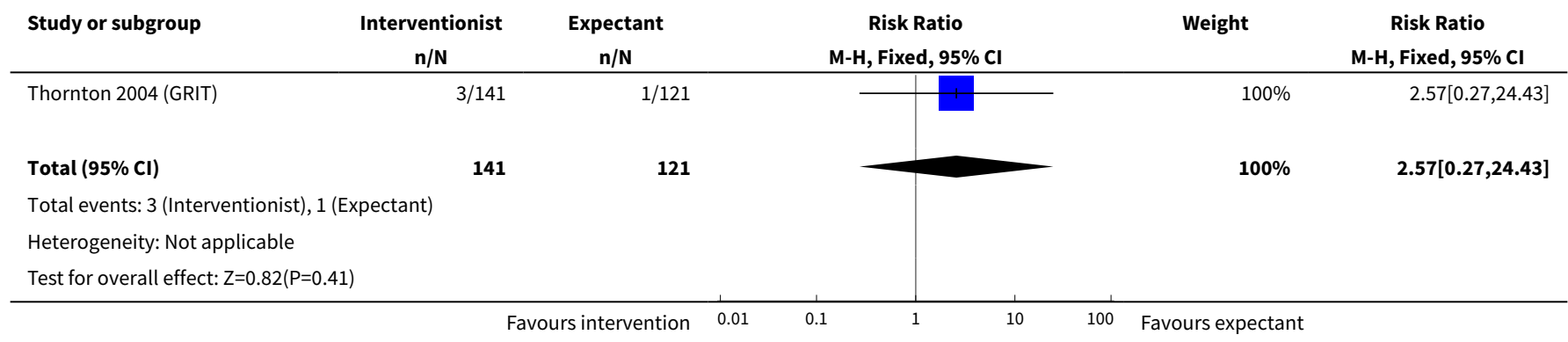

Analysis 1.18. Comparison 1 Interventionist care versus expectant (delayed delivery) care for severe pre-eclampsia, Outcome 18 Measures of long-term growth \& development (cerebral palsy).

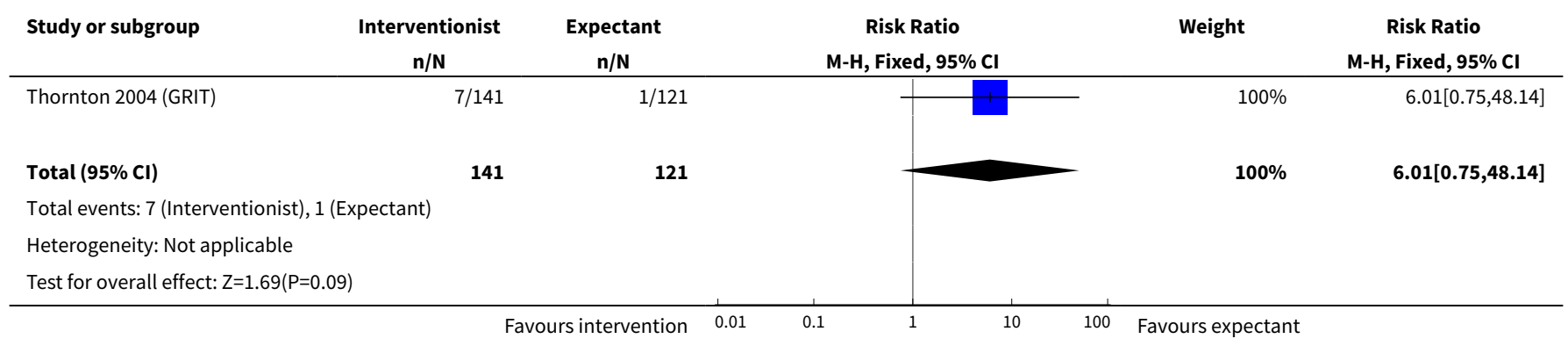

Analysis 1.19. Comparison 1 Interventionist care versus expectant (delayed delivery) care for severe preeclampsia, Outcome 19 Measures of long-term growth \& development (poor hearing, use of hearing aid).

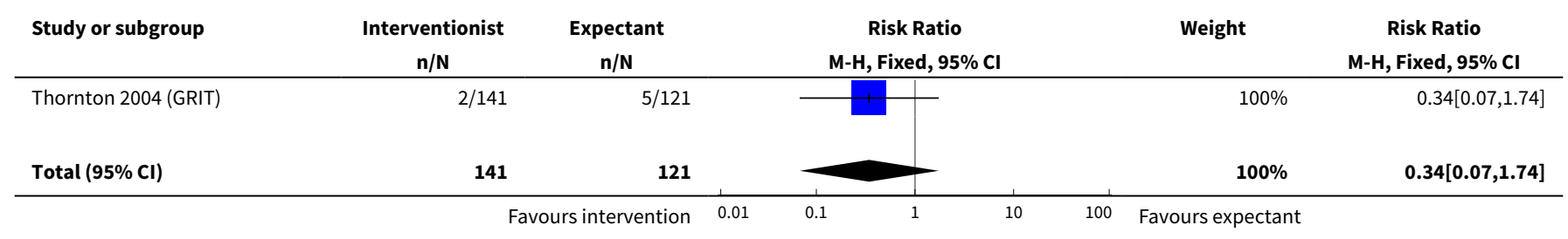




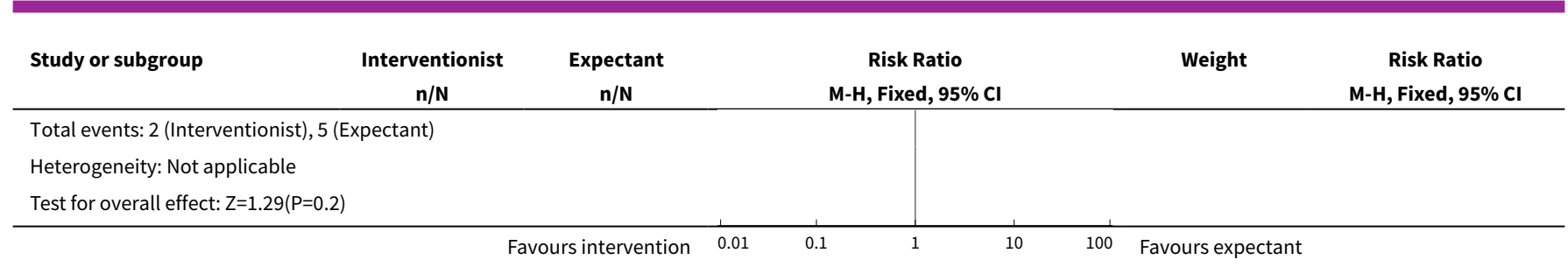

Analysis 1.20. Comparison 1 Interventionist care versus expectant (delayed delivery) care for severe pre-eclampsia, Outcome 20 Measures of long-term growth \& development (impaired vision).

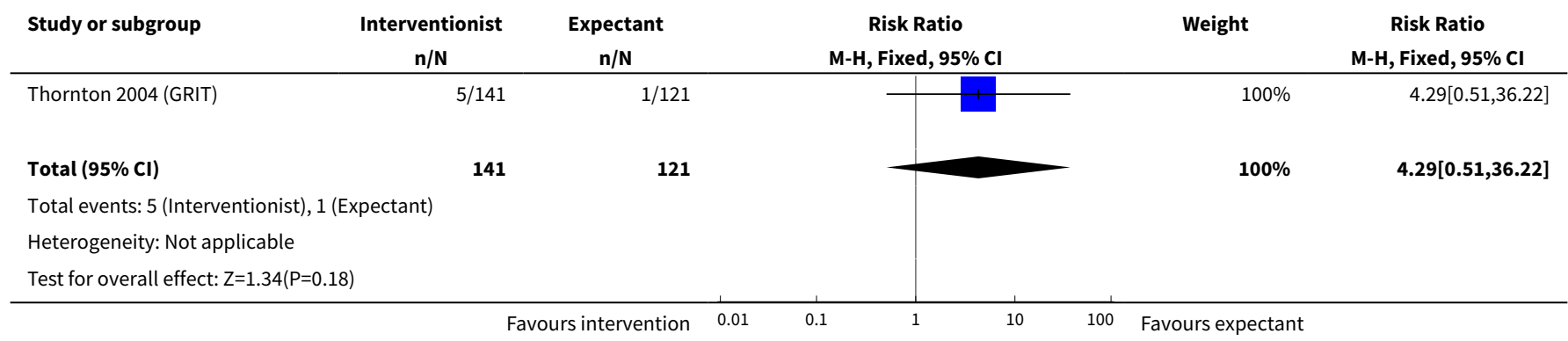

Analysis 1.21. Comparison 1 Interventionist care versus expectant (delayed delivery) care for severe pre-eclampsia, Outcome 21 Admission to neonatal intensive care unit.

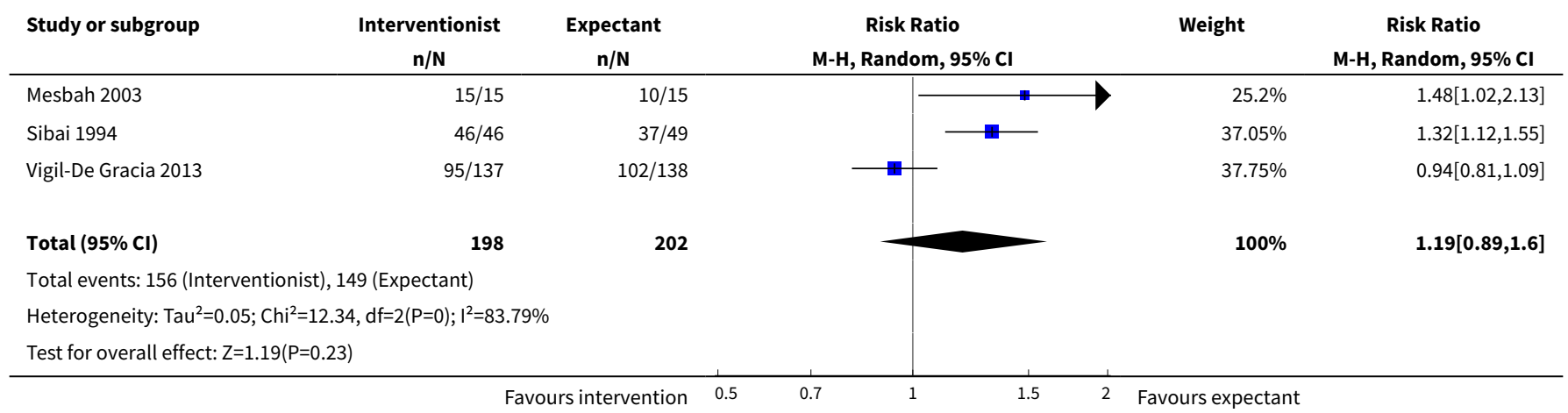

Analysis 1.22. Comparison 1 Interventionist care versus expectant (delayed delivery) care for severe pre-eclampsia, Outcome 22 Length of stay in neonatal intensive care unit (days).

\begin{tabular}{|c|c|c|c|c|c|c|c|c|}
\hline \multirow{3}{*}{$\begin{array}{l}\text { Study or subgroup } \\
\text { Sibai } 1994\end{array}$} & \multicolumn{2}{|c|}{ Interventionist } & \multicolumn{2}{|c|}{ Expectant } & \multirow{2}{*}{\multicolumn{2}{|c|}{$\begin{array}{l}\text { Mean Difference } \\
\text { Random, 95\% Cl }\end{array}$}} & \multirow{3}{*}{$\begin{array}{l}\text { Weight } \\
30.14 \%\end{array}$} & \multirow{3}{*}{$\begin{array}{l}\begin{array}{l}\text { Mean Difference } \\
\text { Random, } 95 \% \mathrm{Cl}\end{array} \\
16.4[10.02,22.78]\end{array}$} \\
\hline & \multirow{2}{*}{$\frac{N}{46}$} & \multirow{2}{*}{$\frac{\text { Mean(SD) }}{36.6(17.4)}$} & \multirow{2}{*}{$\frac{\mathbf{N}}{49}$} & \multirow{2}{*}{$\frac{\text { Mean(SD) }}{20.2(14)}$} & & & & \\
\hline & & & & & & $\longrightarrow$ & & \\
\hline Mesbah 2003 & 15 & $22.3(5.8)$ & 15 & $15.7(4.5)$ & & 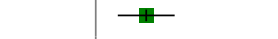 & $34.73 \%$ & $6.6[2.89,10.31]$ \\
\hline Vigil-De Gracia 2013 & 137 & $13.8(14)$ & 138 & $13.4(15)$ & & & $35.14 \%$ & $0.4[-3.03,3.83]$ \\
\hline Total $\star \star \star$ & 198 & & 202 & & & & $100 \%$ & $7.38[-0.45,15.2]$ \\
\hline & & & & tion & -20 & -10 & Favours & \\
\hline
\end{tabular}




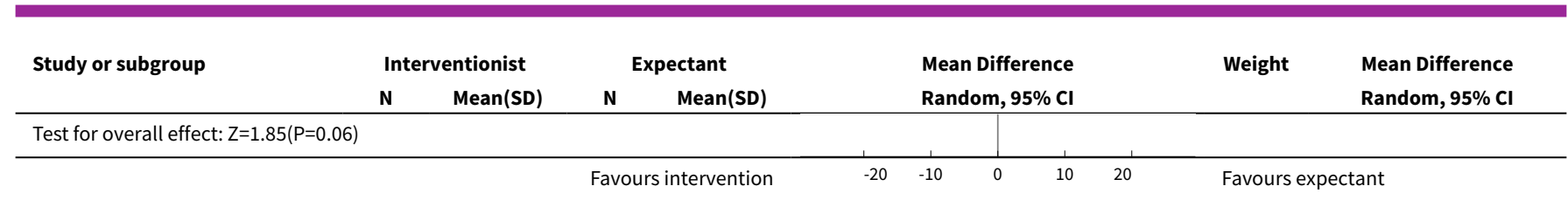

\section{APPENDICES}

\section{Appendix 1. Search methods for ICTRP and ClinicalTrials.gov}

\section{ICTRP}

preeclampsia AND remote AND term

preeclampsia AND expectant

preeclampsia AND "before term"

\section{ClinicalTrials.gov}

Advanced search

Study type: Interventional

Condition: preeclampsia

Other terms: preterm or expectant

\section{WHAT'S NEW}

\begin{tabular}{lll}
\hline Date & Event & Description \\
\hline 27 November 2017 & New search has been performed & $\begin{array}{l}\text { Search updated and two new trials included. The review now in- } \\
\text { cludes six trials with 748 women. A 'Summary of findings' table } \\
\text { was added for this update. }\end{array}$ \\
\hline 27 November 2017 & $\begin{array}{l}\text { New citation required but conclusions } \\
\text { have not changed }\end{array}$ & $\begin{array}{l}\text { The overall conclusions have not changed substantially. In this } \\
\text { update, there was no evidence of a clear difference between } \\
\text { groups for caesarean section, length of stay in the neonatal in- } \\
\text { tensive care unit, or admission to neonatal intensive care unit. }\end{array}$ \\
\hline
\end{tabular}

\section{H IS T ORY}

Protocol first published: Issue 2, 2001

Review first published: Issue 3, 2002

\begin{tabular}{lll}
\hline Date & Event & Description \\
\hline 10 July 2013 & $\begin{array}{l}\text { New citation required and conclusions } \\
\text { have changed }\end{array}$ & $\begin{array}{l}\text { Expectant management may be associated with decreased mor- } \\
\text { bidity for the baby. }\end{array}$ \\
\hline 28 February 2013 & New search has been performed & Search updated. Methods updated. \\
& $\begin{array}{l}\text { Three studies identified from updated search (Duvekot 2011a; } \\
\text { Thornton 2004 (GRIT); Langenveld 2011). One study has been in- }\end{array}$
\end{tabular}




\begin{tabular}{lll}
\hline Date & Event & Description \\
\hline & & $\begin{array}{l}\text { cluded (Thornton 2004 (GRIT)); one is an ongoing study (Duvekot } \\
\text { 2011a); and one study has been excluded (Langenveld 2011). }\end{array}$ \\
& & $\begin{array}{l}\text { One study previously in studies awaiting assessment in the last } \\
\text { update has now been included (Mesbah 2003). }\end{array}$ \\
\hline 16 February 2010 & New search has been performed & $\begin{array}{l}\text { Review updated with new report added to Characteristics of } \\
\text { studies awaiting classification. }\end{array}$ \\
\hline 1 December 2009 & Amended & $\begin{array}{l}\text { Search updated. One new report added to Studies awaiting clas- } \\
\text { sification (Mesbah 2003a). }\end{array}$ \\
\hline 15 May 2008 & Amended & Converted to new review format. \\
\hline
\end{tabular}

\section{CONTRIBUTIONS OFAUTHORS}

DC assessed the new trial for risk of bias, extracted the data, and up-dated the text of the review. MM and HA assessed the new trials for risk of bias, independently extracted the data, and reviewed the final version of the review. LD assessed the new trials for risk of bias and reviewed the final version. JGT and KW reviewed the final version of the review.

\section{DECLARATIONS OF INTEREST}

David Churchill: None

Lelia Duley: LD has been awarded an NIHR research grant for a programme of work on care at very preterm birth.

Jim G Thornton: Jim Thornton is an author on one of the included studies (Thornton 2004 (GRIT)). However, he was not involved in any assessment, data extraction, or data analysis of this trial.

Mahmoud Moussa: None

Hind SM Ali: None

Kate F Walker: None

\section{SOURCES OF SUPPORT}

\section{Internal sources}

- No sources of support supplied

\section{External sources}

- National Institute for Health Research, UK.

2013 update - UK NIHR Programme of centrally-managed pregnancy and childbirth systematic reviews of priority to the NHS and users of the NHS: 10/4001/02

- UNDP/UNFPA/WHO/World Bank Special Programme of Research, Development and Research Training in Human Reproduction-HRP, Switzerland.

\section{DIFFERENCES BETWEEN PROTOCOL AND REVIEW}

In 2013, we updated the methods. We modified the inclusion criteria to define more clearly the criteria for types of participants:

Women with severe pre-eclampsia up to and including 34 weeks' gestation. Severe pre-eclampsia was defined as:

- high blood pressure, $\geq 140 / 90 \mathrm{mmHg}$ on two consecutive occasions four or more hours apart, and proteinuria higher than $300 \mathrm{mg} / 24$ hours, or

- severe hypertension (blood pressure at least $160 \mathrm{mmHg}$ systolic, or $110 \mathrm{mmHg}$ diastolic) alone; or

- hypertension as defined above plus one or more of the following criteria: 
- severe proteinuria (usually at least $3 \mathrm{~g}$ (range $2 \mathrm{~g}$ to $5 \mathrm{~g}$ ) protein in 24 hours, or $3+$ on dipstick);

- reduced urinary volume (less than $500 \mathrm{~mL}$ in 24 hours), upper abdominal pain, pulmonary oedema;

- neurological disturbances (such as headache, visual disturbances, and exaggerated tendon reflexes);

- impaired liver function tests, high serum creatinine, low platelets;

- suspected intrauterine growth restriction or reduced amniotic fluid.

This latter set of criteria reflect the natural history of the disease and clinical practice when diagnosing severe pre-eclampsia.

We defined primary and secondary outcomes.

We incorporated a 'Summary of findings' table into the 2017 update.

In 2017, we added an additional search of ClinicalTrials.gov, the WHO International Clinical Trials Registry Platform (ICTRP).

\section{INDEX TERMS}

\section{Medical Subject Headings (MeSH)}

*Delivery, Obstetric [adverse effects] [methods]; *Watchful Waiting; Cerebral Hemorrhage [epidemiology]; Cesarean Section [statistics \& numerical data]; Eclampsia [epidemiology]; Enterocolitis, Necrotizing [etiology]; HELLP Syndrome [epidemiology]; Hyaline Membrane Disease [etiology]; Perinatal Mortality; Pre-Eclampsia [^therapy]; Pulmonary Edema [epidemiology]; Randomized Controlled Trials as Topic

\section{MeSH check words}

Female; Humans; Infant, Newborn; Pregnancy 